\title{
Some Factors Determining the Degree of Job Satisfaction and Achievement Motivation of some Farmers' Organizations Employees in El-Arish District in North Sinai Governorate
}

Hassan, M. M. and A. E. A. Betah

${ }^{1}$ Rural Sociology Fac.Of Environmental Agricultural Sciences El-Arish University

${ }^{2}$ Rural Sociology College of Agriculture, Saba Basha Alexandria University

\author{
بعض العوامل المحددة لارجة الرضا الوظيفى ودافعية الإنجاز للعاملين ببعض منظمات المزارعين بمركز العريش

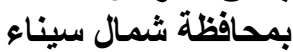

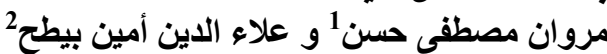

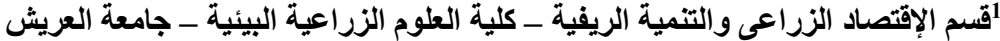

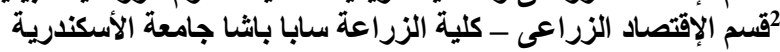 \\ الملخ مـ
}

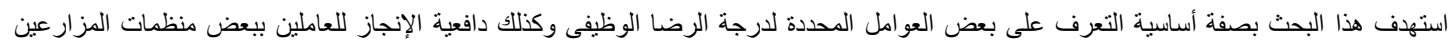

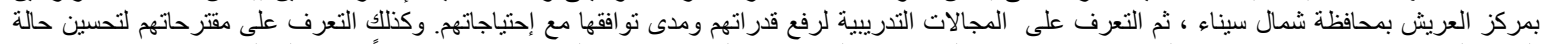

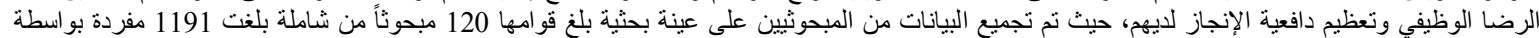

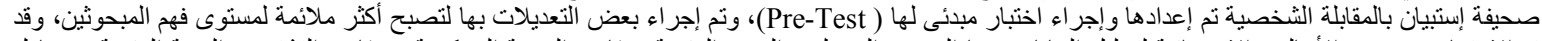

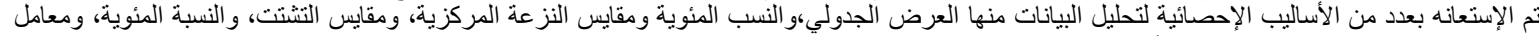

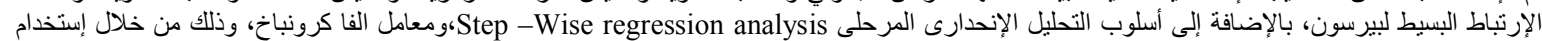

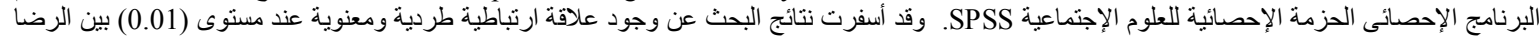

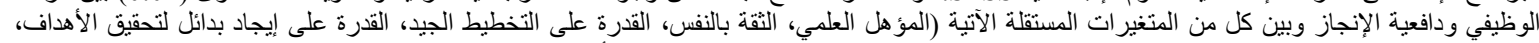

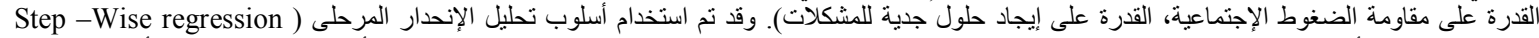

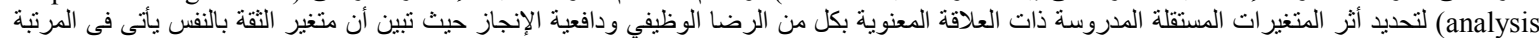

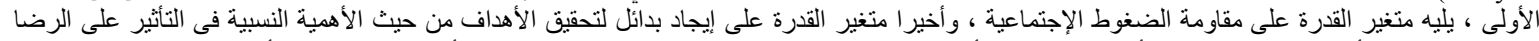

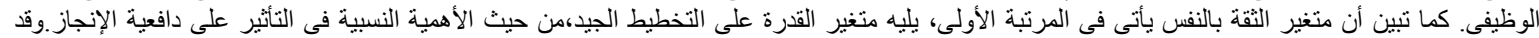

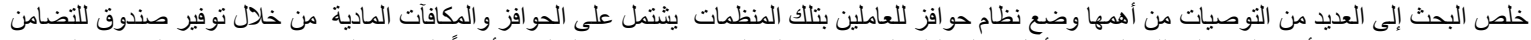

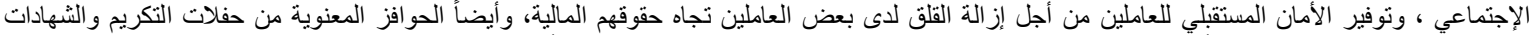

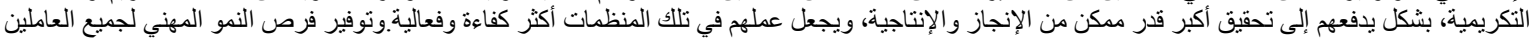

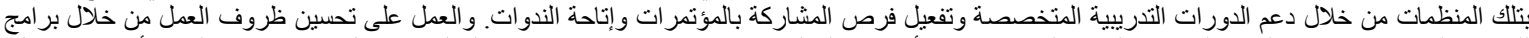

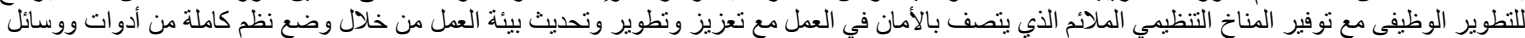

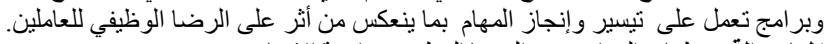
كلمات دالة: منظمات المز علير عين ، الرضا الوظيفى ، دافعية الإنجاز.

يصعب تفسير ها لأنها متغيرة بتغير المواقف المختلفة، فالرضا الوظيفي

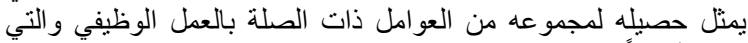

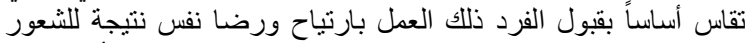

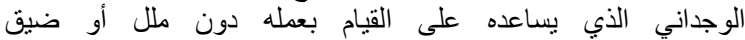

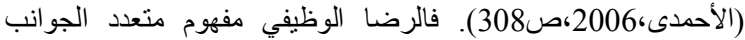

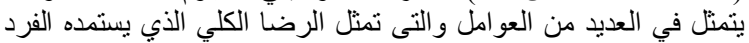

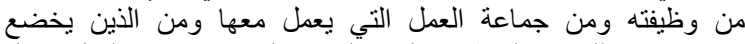

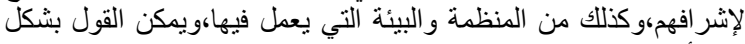

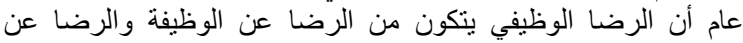

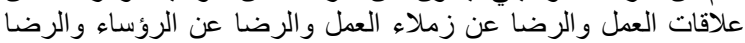

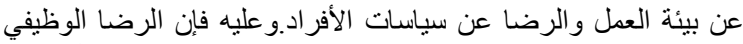

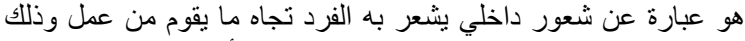

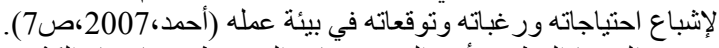

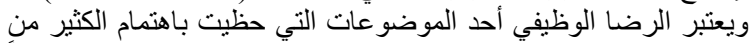

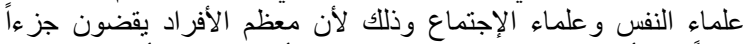

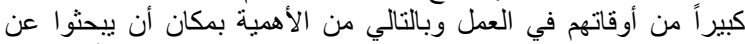

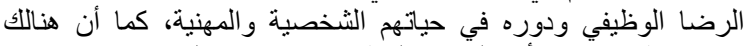

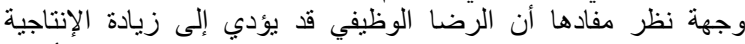

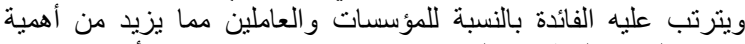

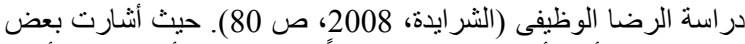

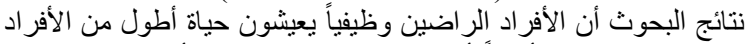

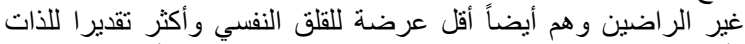

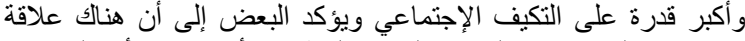

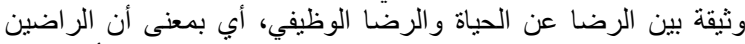

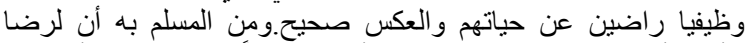

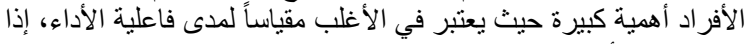

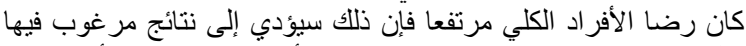

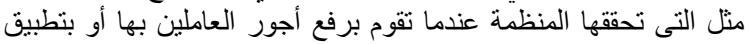

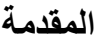

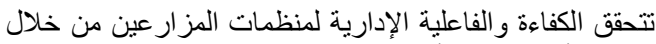

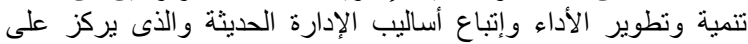

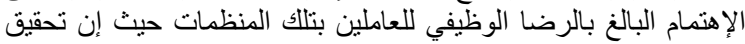

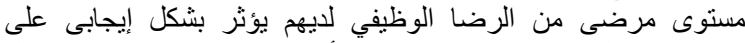

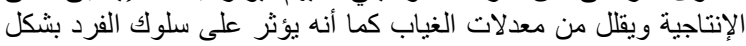

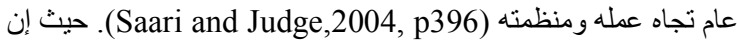

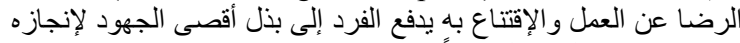

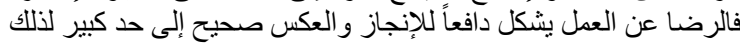

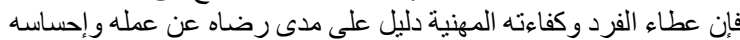

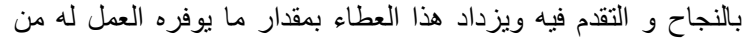

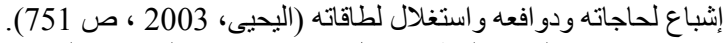

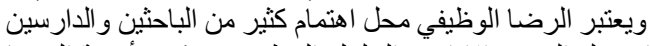

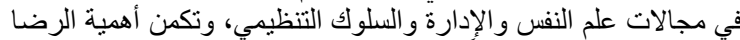

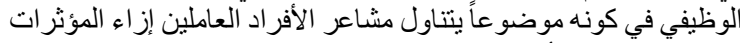

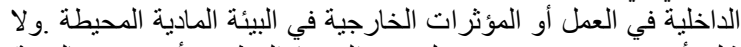

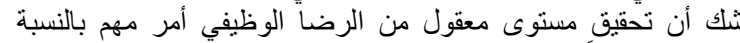

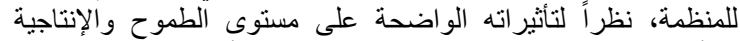

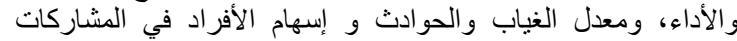

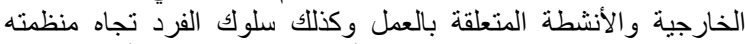

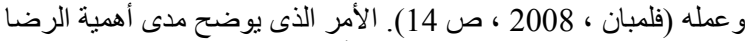

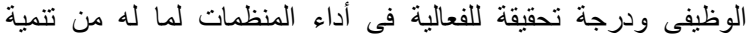

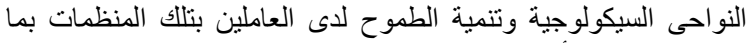
يساهم فى تنمية الأداء ورفع مستوى الإنتاجية.

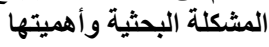

لا يمكن تحديد مفهوم الرضا الوظيفي إلوني بتعريف بذاته فهو متعدد المعاني، و السبب فى ذلك برجع إلى إرتباطه بمشاعر الأفراد التي غالبه فيا ما 


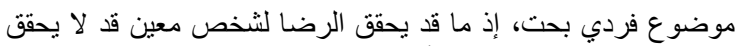

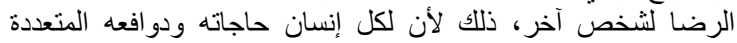

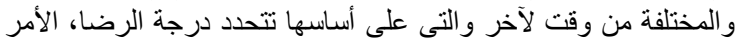

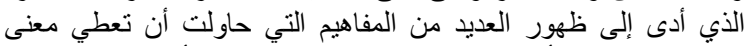

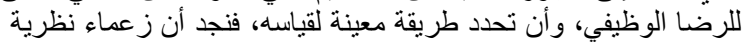

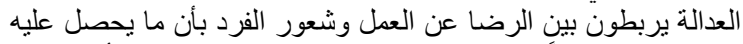

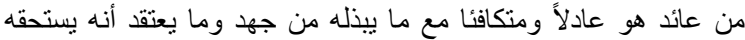

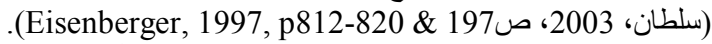
حيث يرتبط الرضا الوظيفي بمشاعر الفرد العامل والذهى يتحدد الزئه

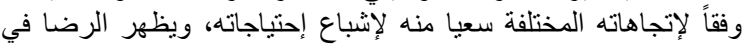

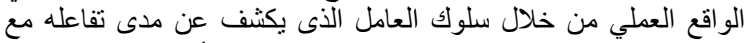

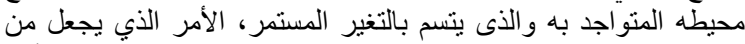

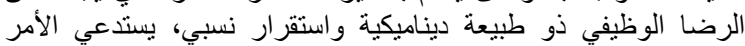

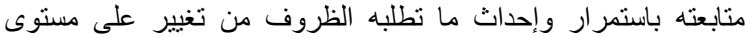

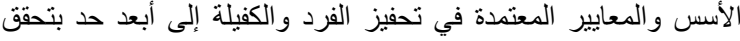

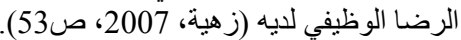
وقد تباينت وجهات نظر الباحثين حول تحديد الإيد العو امل التي تؤثر

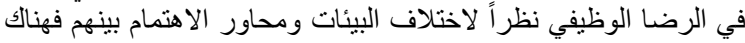

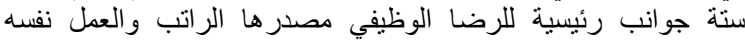

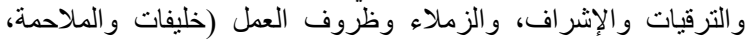

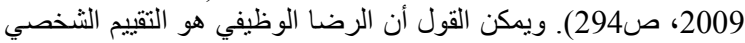

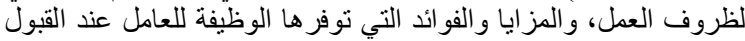

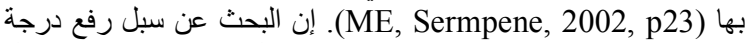

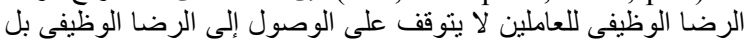

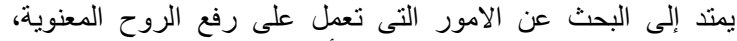

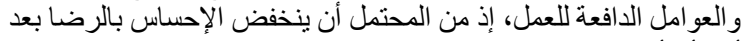

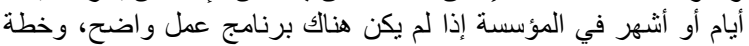

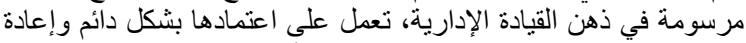

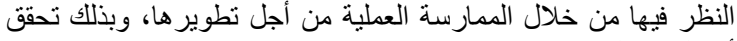

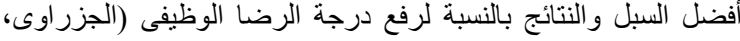

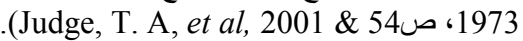

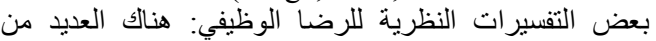

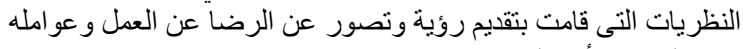

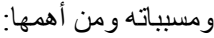

1- نظرية الإدارة العلمية: قام بتأسيس هذه النظرية كل من تايلور

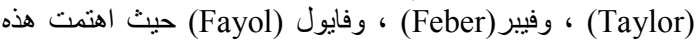

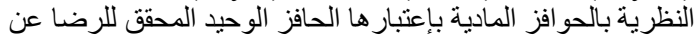

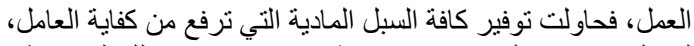

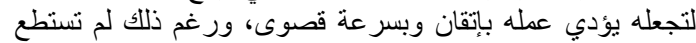

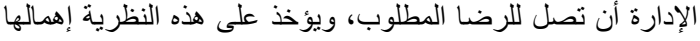

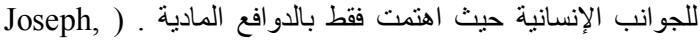
(1993, P: 3758 2- نظرية العاملين:قام بوضعها هرزبرج (Harzberg) وهي ترنبط

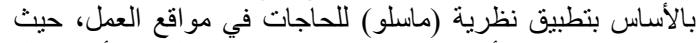

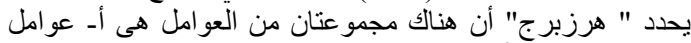

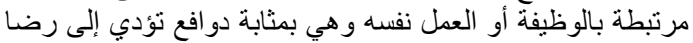

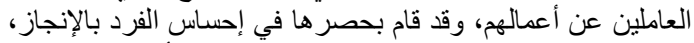

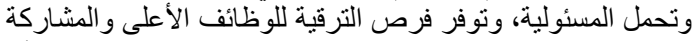

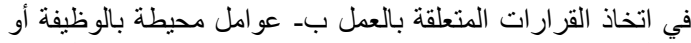

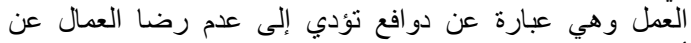

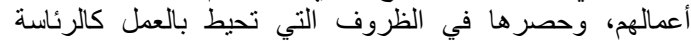

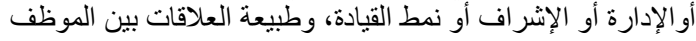

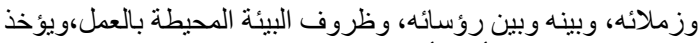

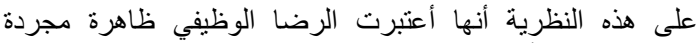

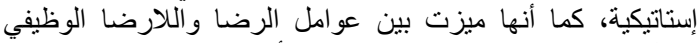

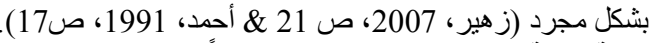

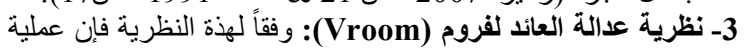

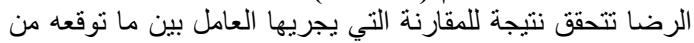

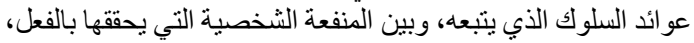

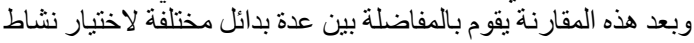

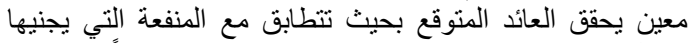
بالفعل، و هذه المنفعة تضم الجانبين المادي و المعنوي معاً، وتفتر لئن

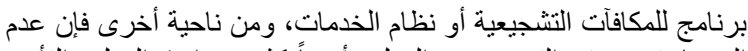

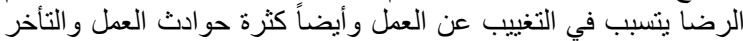

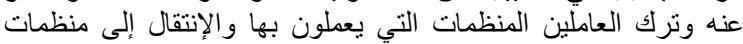

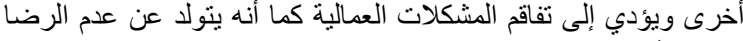

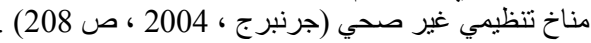
حيث إن تحقيق الرضا الوظيفى يؤدى الى زئى زيادة درجة ولاء

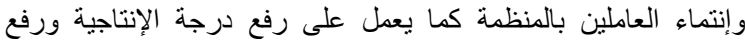

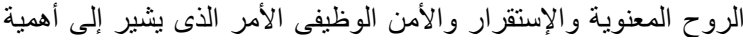

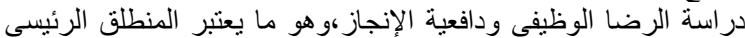

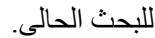
أهداف البحث

أستهدف البحث بصفة أساسية التعرف بعض العوام امل المحددة

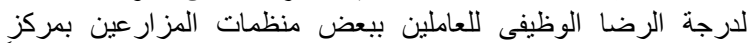
العريش بمحافظة شمال سيناء وكذلك دافعية الإنجاز لذات الذات الفئة، واتساقاً

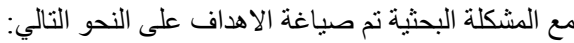

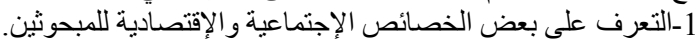
2-التعرف على درجة الرضا الوظيفى للعاملين بالمنظمات الإجتماعية الإعية المدروسة و العو امل المرتبطة بها.

3-التعرف على درجة دافعية الإنجاز للعاملين بالمنظمات المرات الإجتماعية

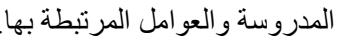

4-التعرف على المجالات التدرييية لرفع قدراتية الترات العاملين في منظمات

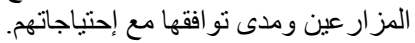

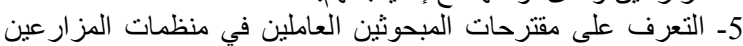

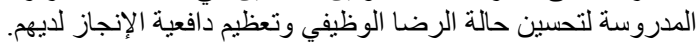

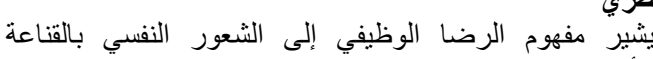
الإطار النظري

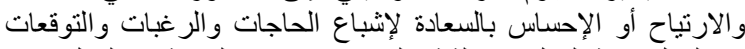

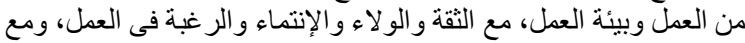

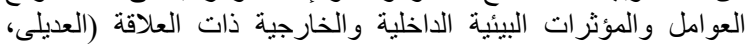

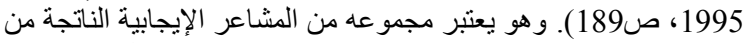

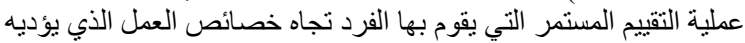

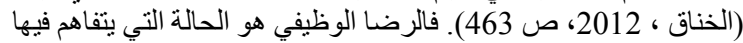

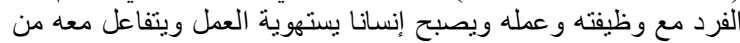

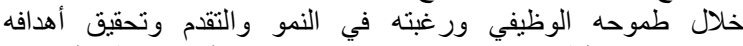

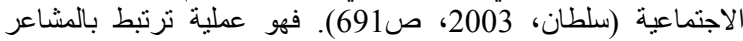

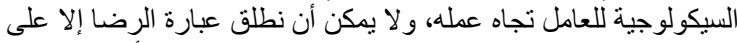

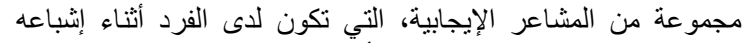

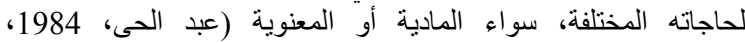

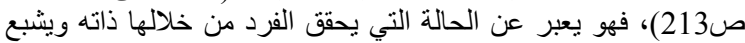

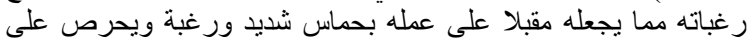

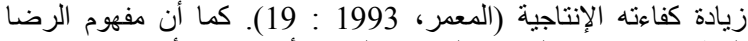

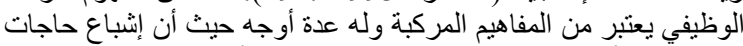

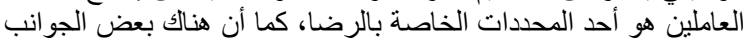

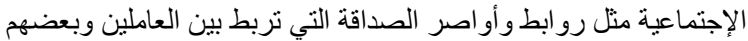

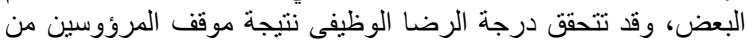

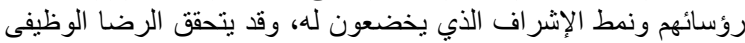

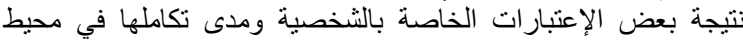

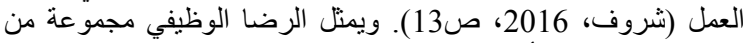

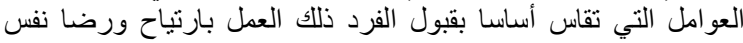

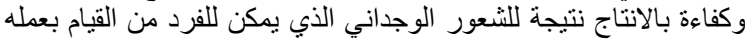

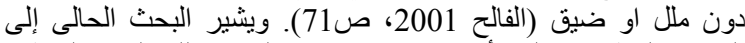

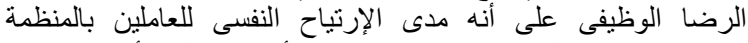

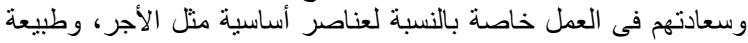
العمل وظروفة، وفرص العمل الترقية، وطبيعة العلاقة بين العاملين داخل الإنل وطبئ

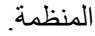

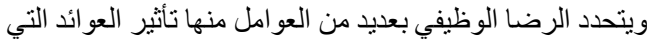

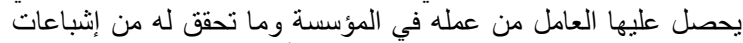

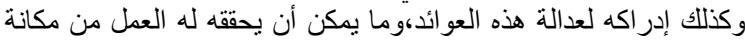

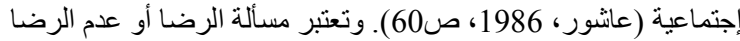

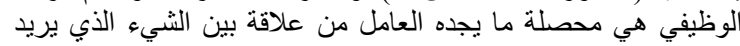

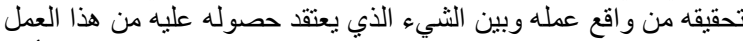

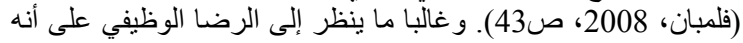




\section{J. Agric. Econom. and Social Sci., Mansoura Univ., Vol. 9 (2), February, 2018}

أن العامل الراضي عن عمله هو أكثر استعدادا للاستمر ار بعملة وتحقيق

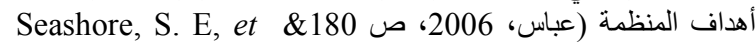
.(al,1975, p333-368

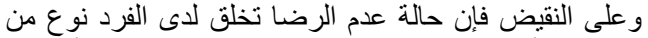

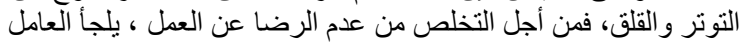

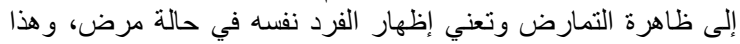

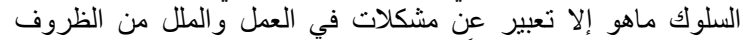

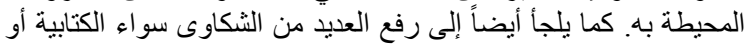

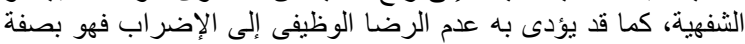

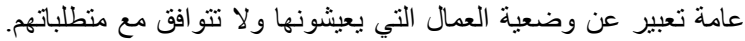

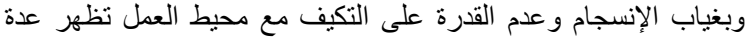

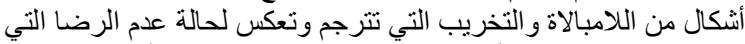

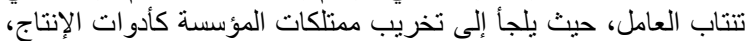

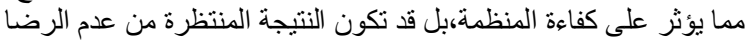

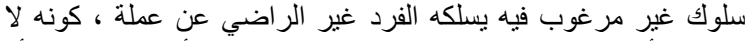

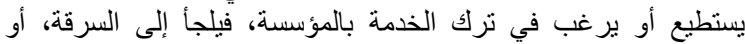

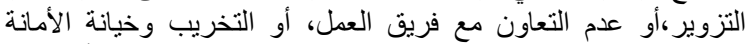

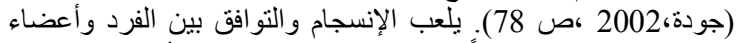

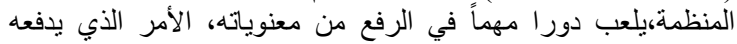

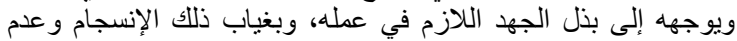
القدرة على التكيف مع محيط العمل نظهر عدة التهل أشكال من التلامبالاة

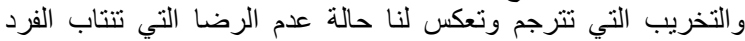

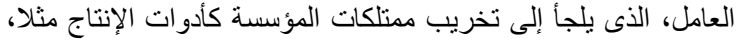

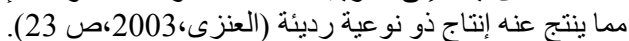

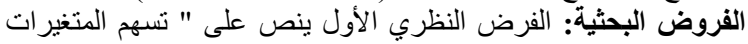

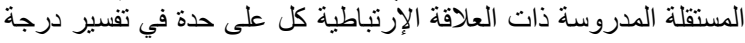

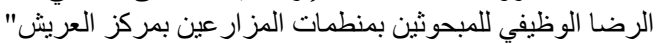

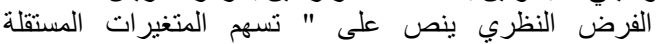

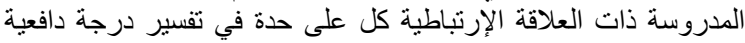

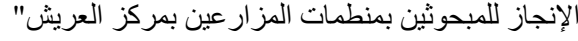

\section{الطريقة البحثية}

أـ شاملة البحث وعينته: يتناول البحث العاملين في منظمات المزارعين

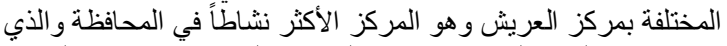

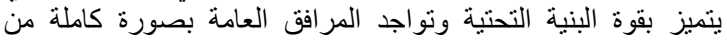

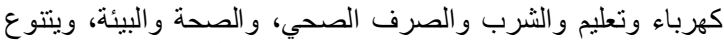

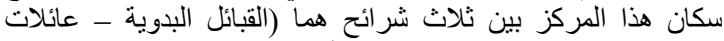

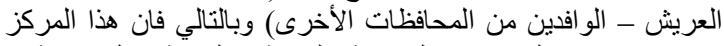

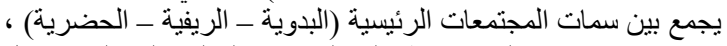

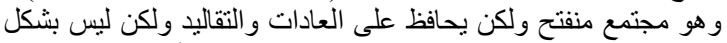

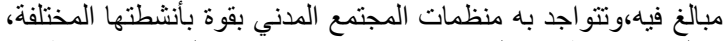

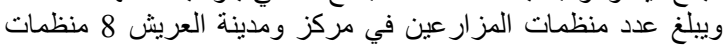

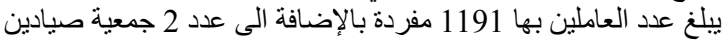

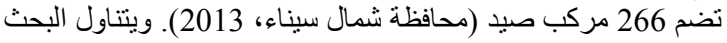

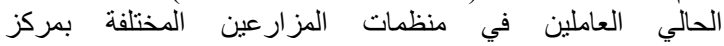

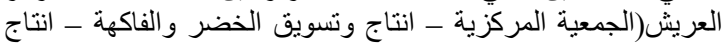

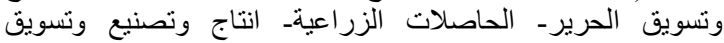

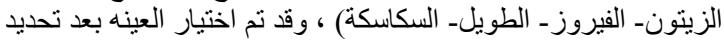

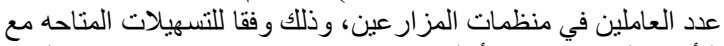

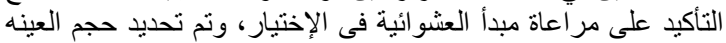

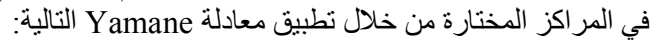
$\mathbf{N}$

$$
\text { n }
$$

B = خطأ الثقاير بافتراض أن خطأ التقاير 9 \% (سلامة،2016\& العزبي، 2017).

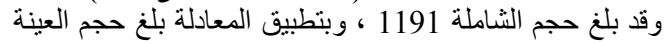

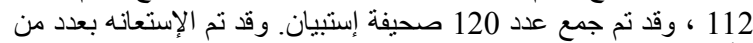

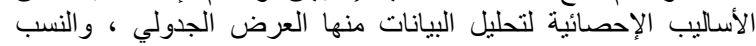

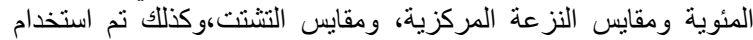
أسلوب تحليل الإنحدار المرحلى لتحديد أثر المتغيرات المستقلة المدروسة

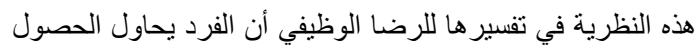

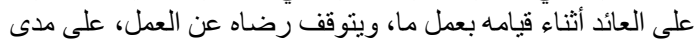

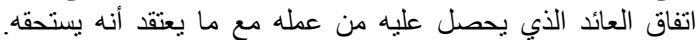
(Tharrington, 1993, P. 2198)

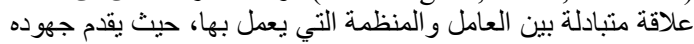

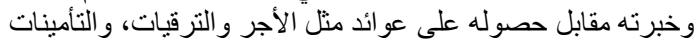

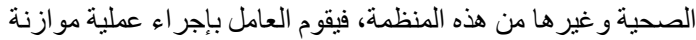

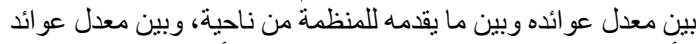

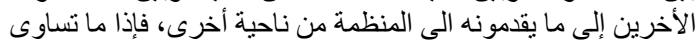

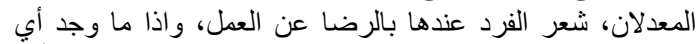

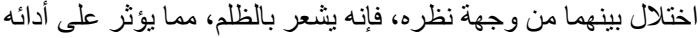

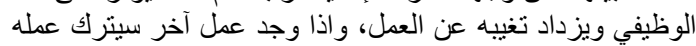

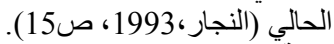

4- نظرية تلاعيم السلوك لسكينر:تعتبر هذه النظرية إحدى نطورات نظريات

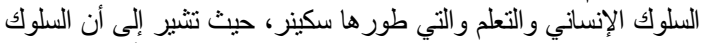

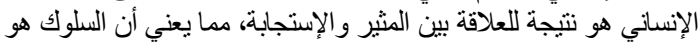

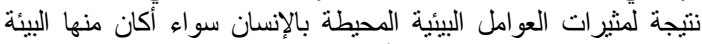

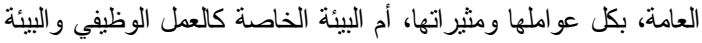

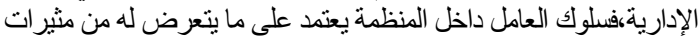

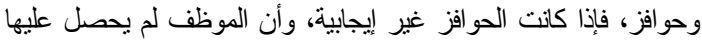

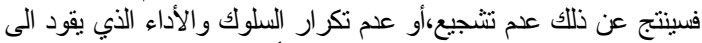

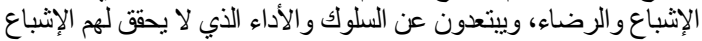

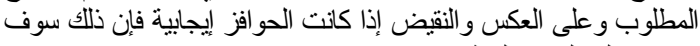

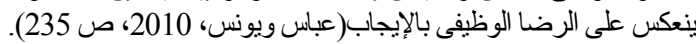

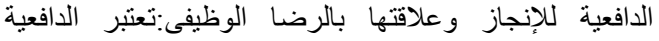

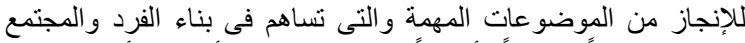

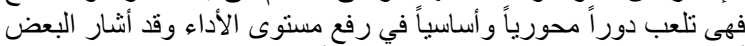

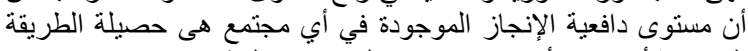

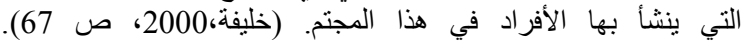

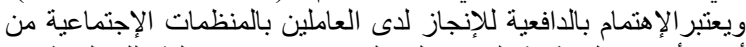

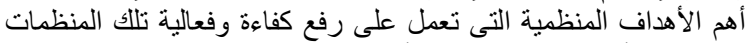

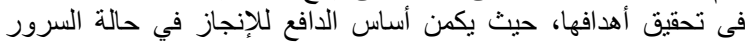

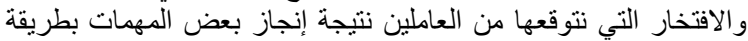

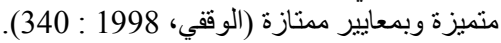

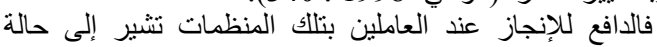

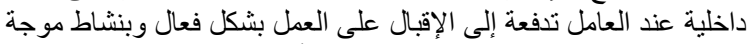

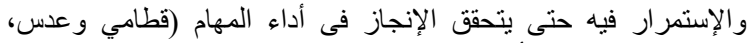

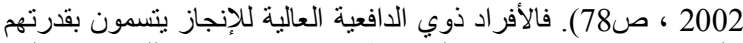

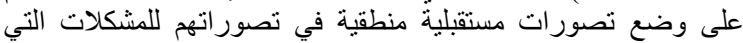

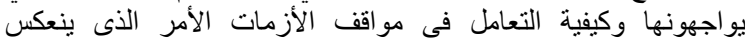

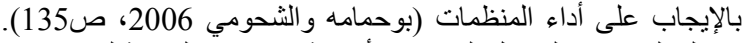

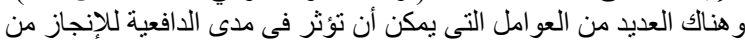

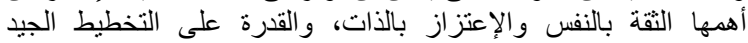

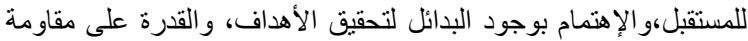

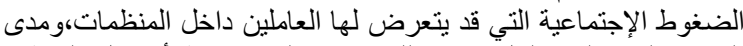

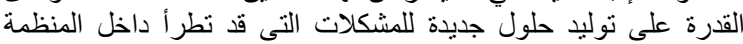

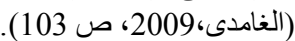

آثار الرضا الوظيفي: لقد أنشار البعض أن العمال الأكثر رضاءاً

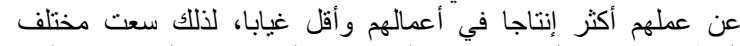

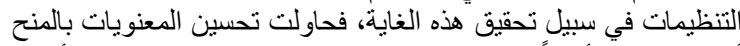

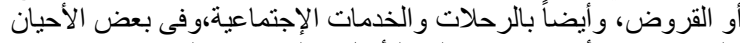

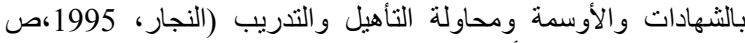

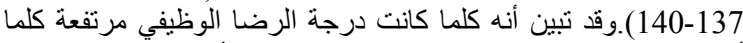

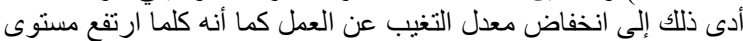

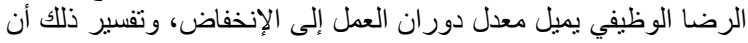

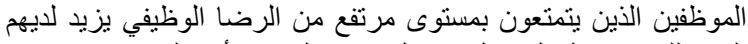

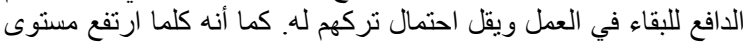

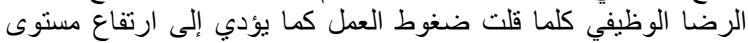

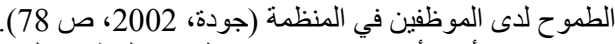

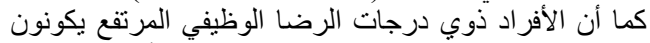

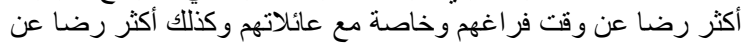

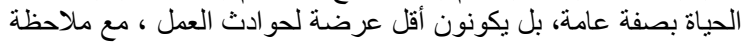


نو افرت معايا فلوس هفتح مشروع خاص بجانب الوظيفة،ضرورة

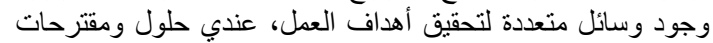

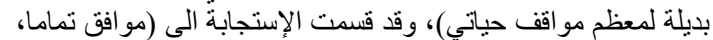

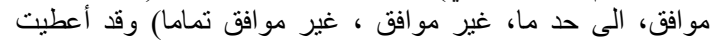

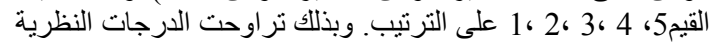

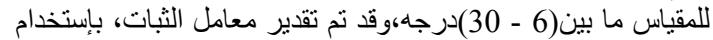

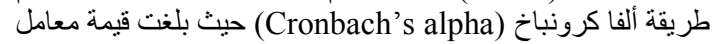

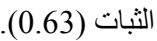

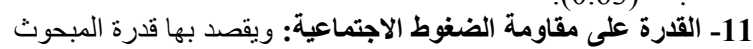

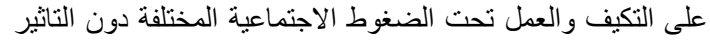

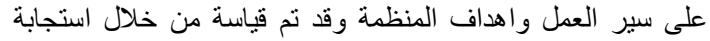

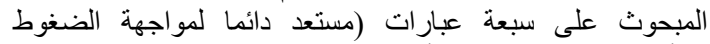

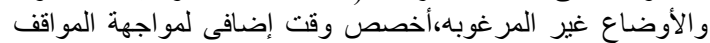

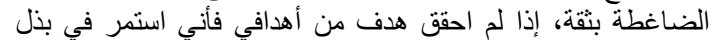

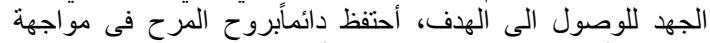

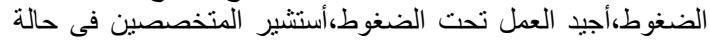

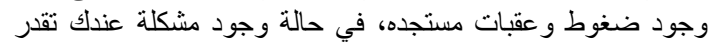

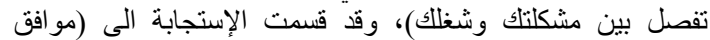

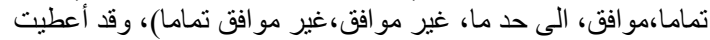

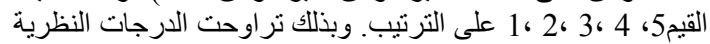

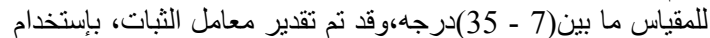

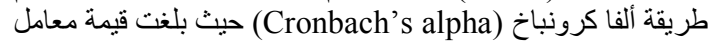
الثبات (0.66).

12-القدرة على إيجاد حلول جلات جليدة للمشكلات: ويقصد بها القدرة

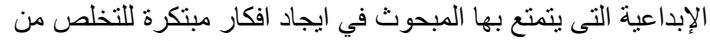

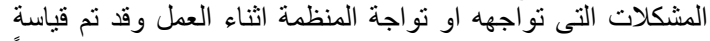

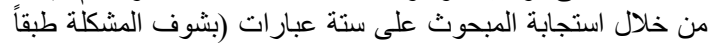

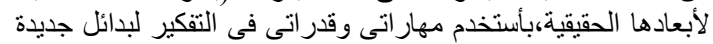

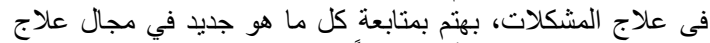

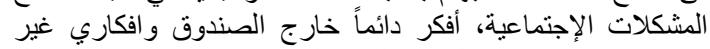

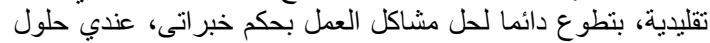

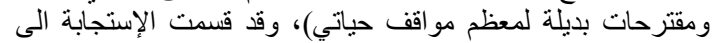

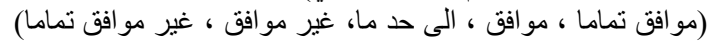

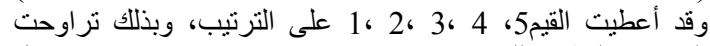

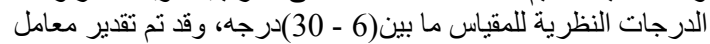

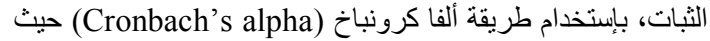

بلغت قيمة معامل الثبات (0.81).

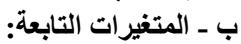

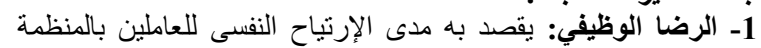

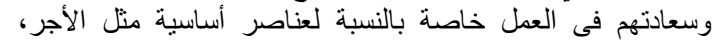

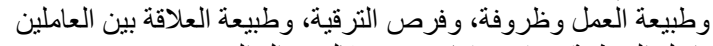

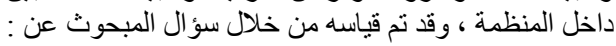

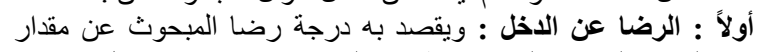

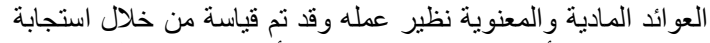

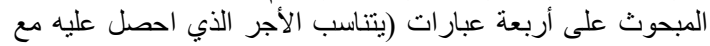

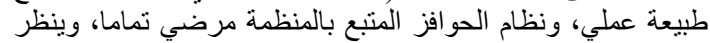

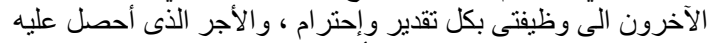

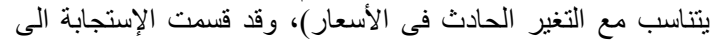

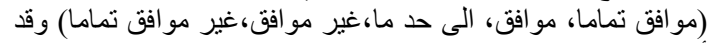

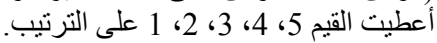

ثانياً : طبيعة ألعمل وظروفه

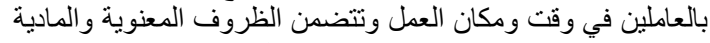

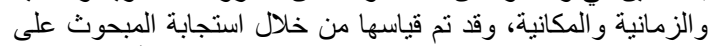

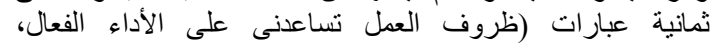

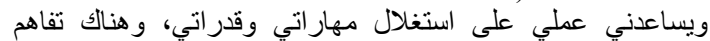
وتعاون مستمر بيني وبين زملائي بالمنظمة، ويتوفر جو من الماني الود

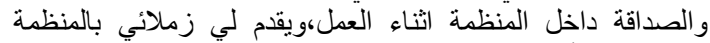

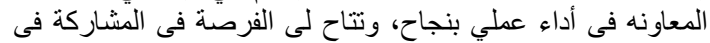

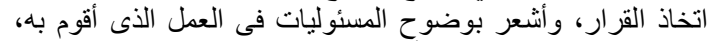

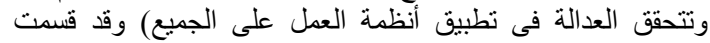

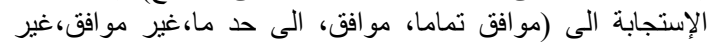

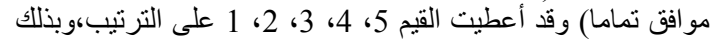

ذات العلاقة المعنوية بدرجة الرضا الوظيفى ودافعية الانجاز للعاملين

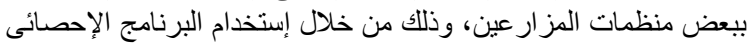

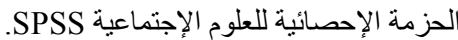

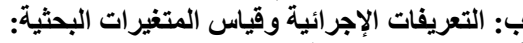
أـ المتغيرات المستقلة : الإجرانة

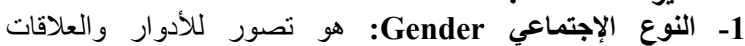

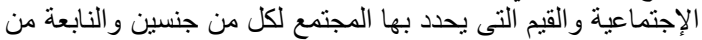

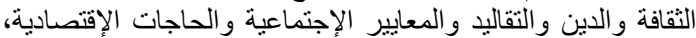

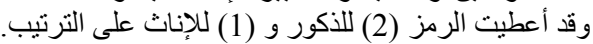

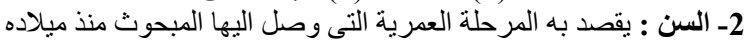

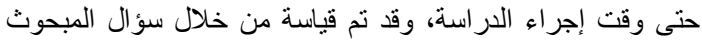

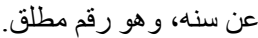

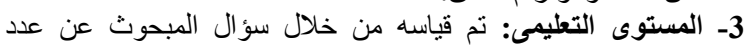

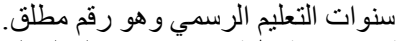

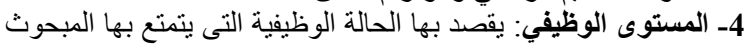

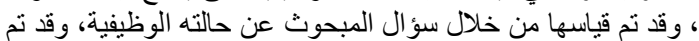

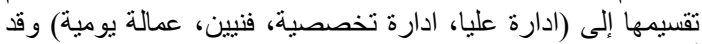

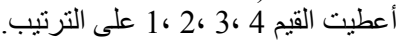

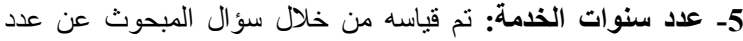

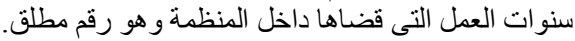

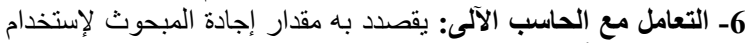

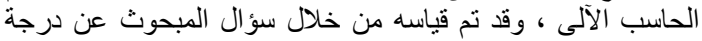

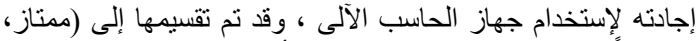

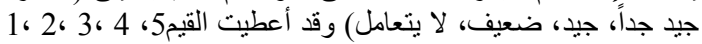

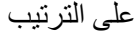

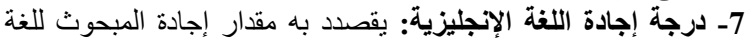

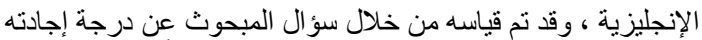

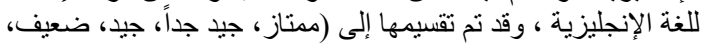

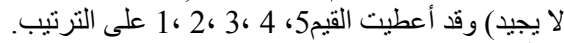

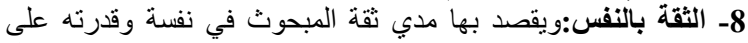

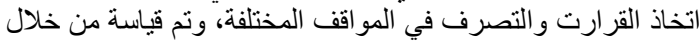

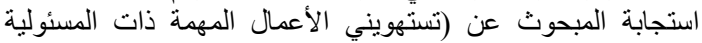

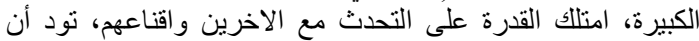

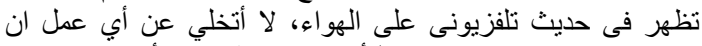

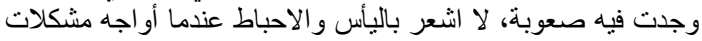

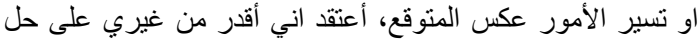

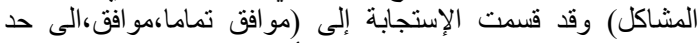

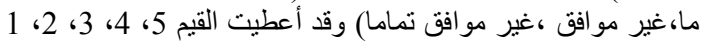

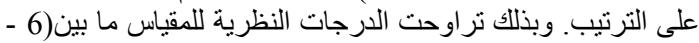

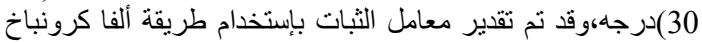

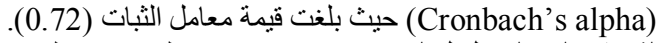

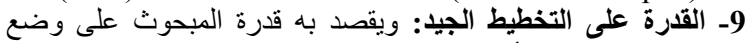

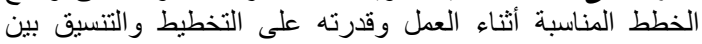

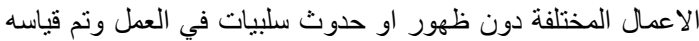

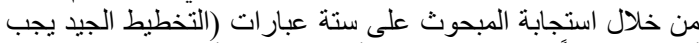

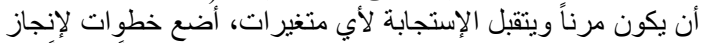

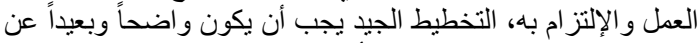

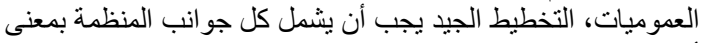

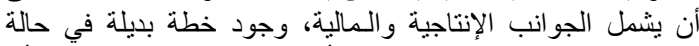

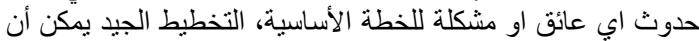

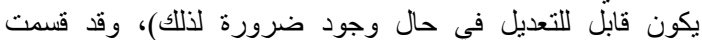

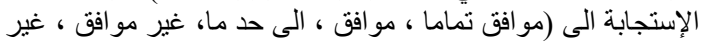

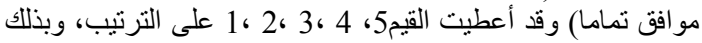

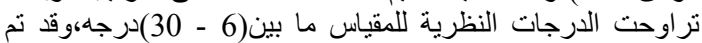
تقدير معامل الثبات بإستخدام طريقة ألفا كرونباخ ( alpha حيث بلغت قيمة معامل الثبات (0.81).

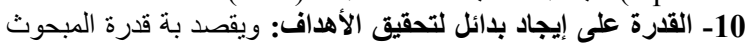

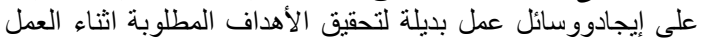

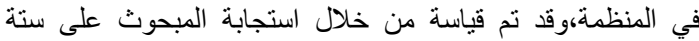

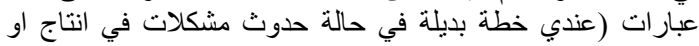

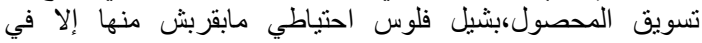

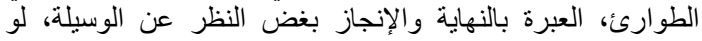




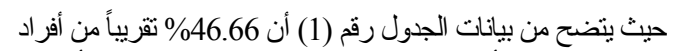

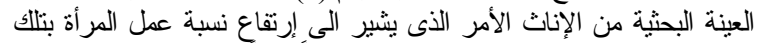

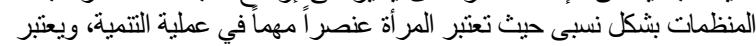

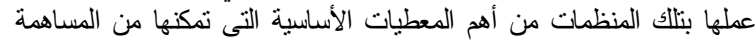

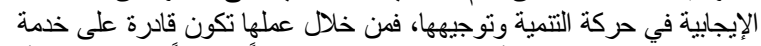

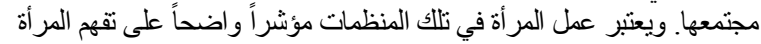
بدور ها في بناء المجتمع وقترتها على المشاركة الحققية في التنمية.

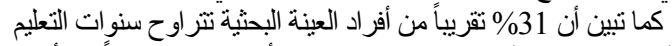

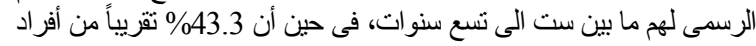

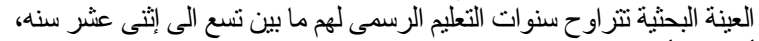

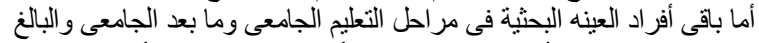

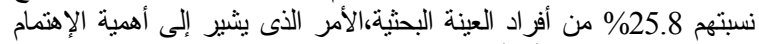

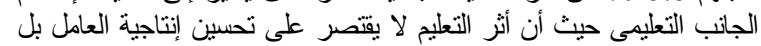

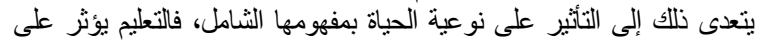

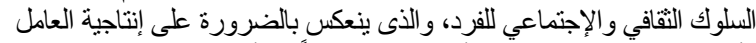

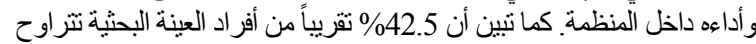

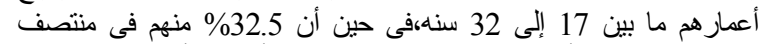

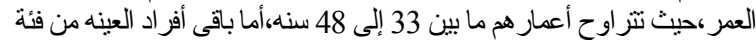
كبار السن حيث تتزاوح أعمار هم ما بين 49 إلى 60 سنه.

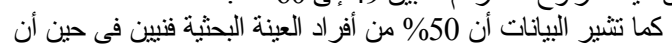

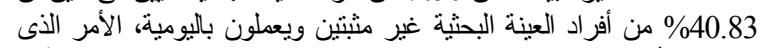

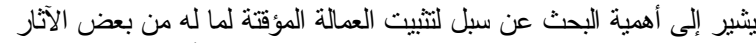

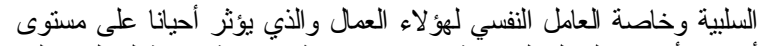

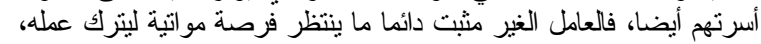

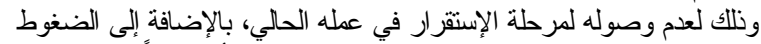

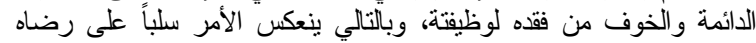
الوظيفى ومن ثم أداء لعطله.

في حين أن31.66\% من أفراد العينة البحثية عدد سنوات الخدمة لهم

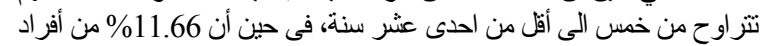

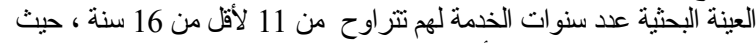

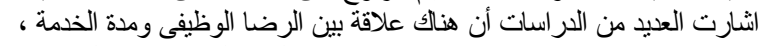

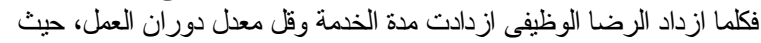

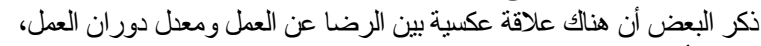
بمغنى أنه كلما ارتفع الرضا عن العند العمل، يميل دوران العمل إلى الإنخفاض (سلطان، 2004 ،ص204: العطية، 2003 :ص الص 109).

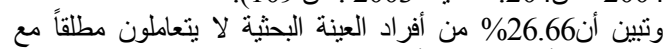

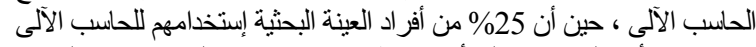

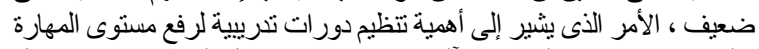

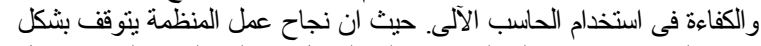

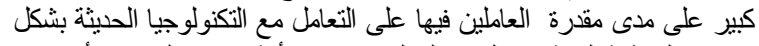

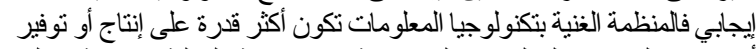

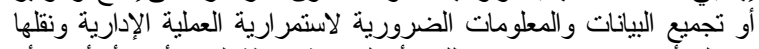

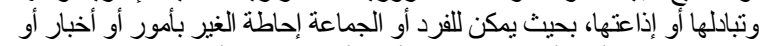

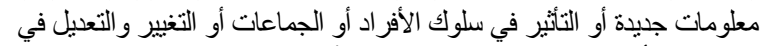

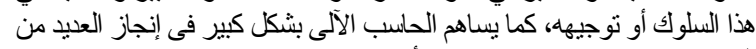

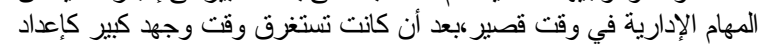

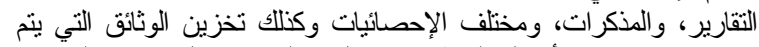

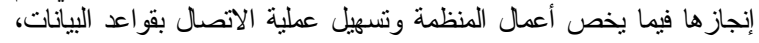
ونللك عن طريق منظومة الثبكات المتصلة بجهاز الحاسب.

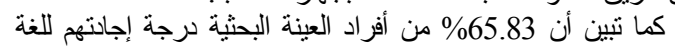

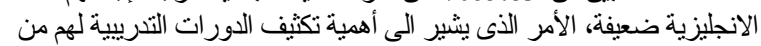

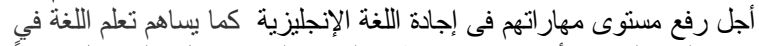

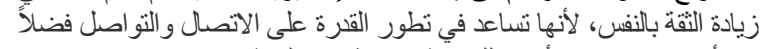

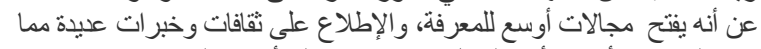
يكون له كبير الأثر فى أداء العامل ورفع قلرته على أداء عمله.

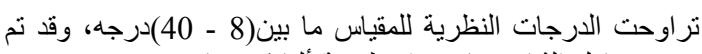

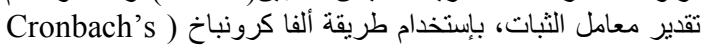
(alpha حيث بلغت قيمة معامل الثبات (0.71).

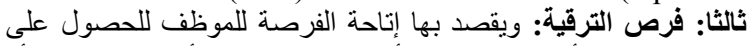

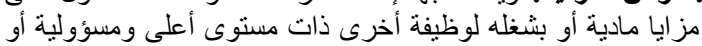

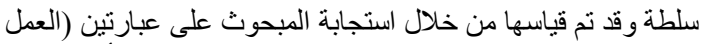

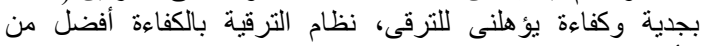

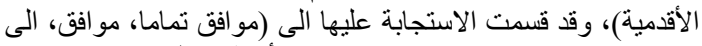

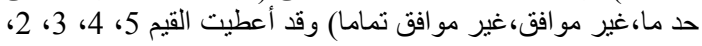
1

رابعاً: طبيعة العلاقة بين العاملين داخل المنظمة: ويقصد بها مدى تحقيق

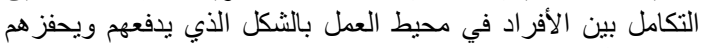

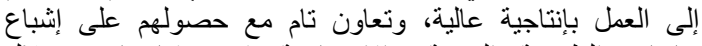

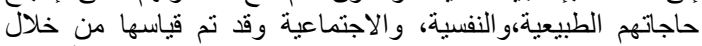

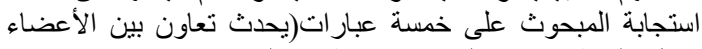

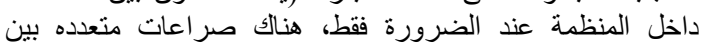

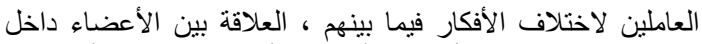

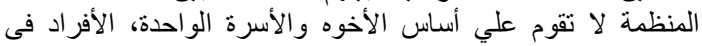

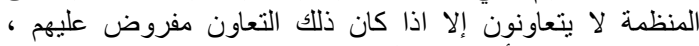

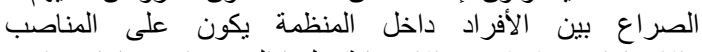

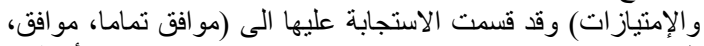

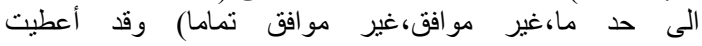

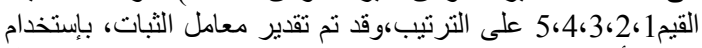
طريقة ألفا كرونباخ (Cronbach's alpha) حيث بلغت قيمة معامل

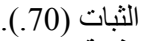

2- دافعية الإنجاز : ويقصد بها الحافز للسعى إلى النجاح وتحقيق نهاية

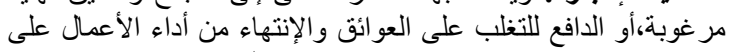

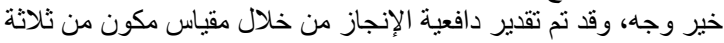
عشر عبارة مقسمة الى مجمو عتين عبار التات إيجابية وهي (يعجبني الذين الذين

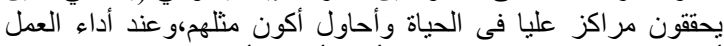

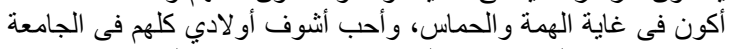

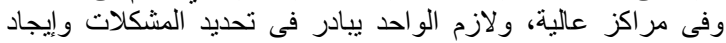

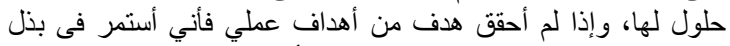

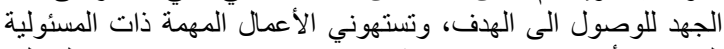

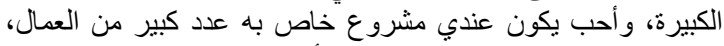

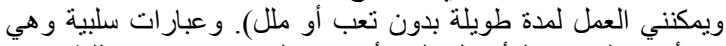

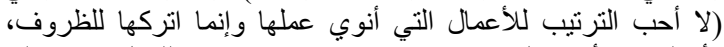

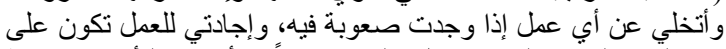

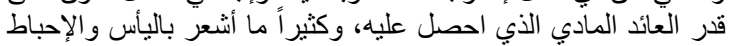

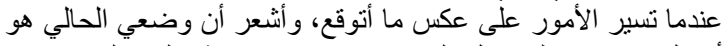

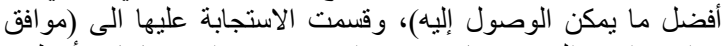

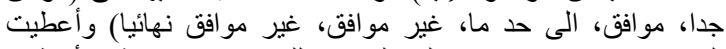

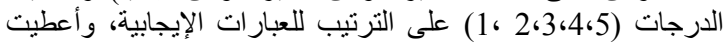

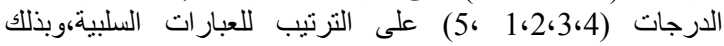

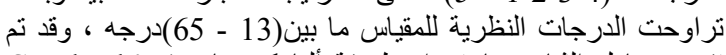

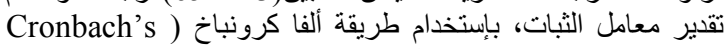
(alpha حيث بلغت قيمة معامل الثبات(0.84).

\section{النتائج و المناقشات}

أولا : الخصائص الإجتماعية والإقتصادية للمبحوثين:

يوضح الجدول رقم (1) الخصائص الإجتمائماعية والإقتصادية

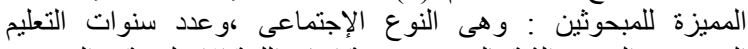

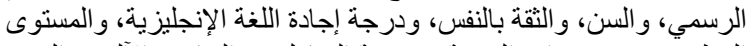
الوظيفي،و عدد سنو ات الخدمة، ودرجة التعامل مع الحاسب الآلى الكي، والقدرة على التخطيط الجيد، والقدرة على إيجاد بدائل لتحقيق الأهداف، والثلى والقدرة على مقاومة الضغوط الإجتماعية، والقدرة على إيجاد حلول جيدة 
Hassan, M. M. and A. E. A. Betah

جدول 1. التوزيع العددى والنسبى للمبحوثين وفقاً للخصائص الإجتماعية والإقتصادية و النفسية

\begin{tabular}{|c|c|c|c|c|c|}
\hline$\%$ & العدد & 2- عدد سنوات التعليم الرسمي. & $\%$ & العدد & 1- النوع الإجتماعى. \\
\hline 30.9 & 37 & تعليم أساسى(6-9). & 53.33 & 64 & 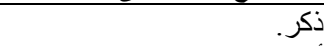 \\
\hline 43.3 & 52 & فنى وما يعادله (9-12). & 46.66 & 56 & 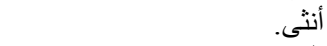 \\
\hline \multirow[t]{2}{*}{25.8} & 31 & جامعى وما فوق جامعى 13 فأكثر. & 100 & 120 & 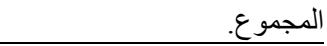 \\
\hline & & 4- التقة بالنفس. & & & 3- السن. \\
\hline 32.5 & 39 & منخفض (6-14). & 42.5 & 51 & حديث التعيين(17-32). \\
\hline 51.6 & 62 & متوسط (15-22). & 32.5 & 39 & متوسط(33-48). \\
\hline \multirow[t]{2}{*}{15.9} & 19 & مرتفع (23-30). & 25 & 30 & قديم(49-60). \\
\hline & & 6-المستوى الوظيفي. & & & 5-درجة إجادة اللغة الإنجليزية. \\
\hline 4.16 & 5 & ادارة عليا. & 3.33 & 4 & ممتاز. \\
\hline 5 & 6 & ادارة تخصصية. & 4.16 & 5 & جيد جدا. \\
\hline 50 & 60 & فنيين. & 26.66 & 32 & \\
\hline \multirow[t]{2}{*}{40.83} & 49 & عمالة يو مية. & 65.83 & 79 & ضعيف. \\
\hline & & 8-درجة التعامل مع الحاسب الآلى. & & & 7-عدد سنو ات الخدمة. \\
\hline 3.33 & 4 & 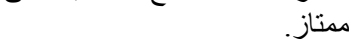 & 30 & 36 & أقل من 5 سنوات. \\
\hline 11.66 & 14 & جيد جدا. & 31.66 & 38 & من 5- لأقل من 11 سنة. \\
\hline 33.33 & 40 & جيد. & 11.66 & 14 & من 11 لأقل من 16 سنة. \\
\hline 25 & 30 & ضعيف. & 13.33 & 16 & من 16 - لأقل من 20 سنة. \\
\hline \multirow[t]{2}{*}{26.66} & 32 & لا لتتعامل. & 13.33 & 16 & 20 سنة فأكثر \\
\hline & & 10- القدرة على إيجاد بدائل لتحقيق & & & 9-القدرة على التخطيط الجيد. \\
\hline 24.1 & 29 & منخفض (6-14). & 32.5 & 39 & منخفض (6-14). \\
\hline 59.1 & 71 & متوسط (15-22). & 51.6 & 62 & متوسط (23-22). \\
\hline \multirow[t]{2}{*}{16.8} & 20 & مرتفع (23-30). & 15.9 & 19 & مرتفع (23-30). \\
\hline & & 12-القدرة على إيجاد حلول جيدة للا & & \multicolumn{2}{|c|}{ 11-القدرة على مقاومة الضغوط الإجتماعية. } \\
\hline 16.7 & 20 & منخفض (6-13). & 18.3 & 22 & منخفض (6-13). \\
\hline 65.8 & 79 & متوسط (14-25). & 61.7 & 74 & متوسط (14-24). \\
\hline 17.5 & 21 & مرتفع (26-30). & 20 & 24 & مرتفع (25-30). \\
\hline
\end{tabular}

جدول 3. قيم معاملات الإرتباط بين الرضا الوظيفي وبين العوامل

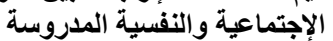

\begin{tabular}{|c|c|c|}
\hline قيم معامل الإرتباط & العوامل الإجتماعية و النفسية & م \\
\hline $0.064-$ & السن. السن. & 1 \\
\hline$* * 0.577$ & المؤهل & 2 \\
\hline $0.134-$ & المستوي & 3 \\
\hline 0.047 & عدد سنوات الخدمة. & 4 \\
\hline 0.147 & 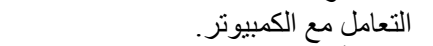 & 5 \\
\hline 0.122 & درجة أجادة اللغة الإنجليزية. & 6 \\
\hline$* * 0.842$ & الثقة بالنفس. & 7 \\
\hline$* * 0.675$ & القدرة على التخطيط الجيد. & 8 \\
\hline$* * 0.430$ & القدرة على إيجاد بدائل لتحقيق الأهداف. & 9 \\
\hline$* * 0.696$ & 1 القدرة على مقاومة الضغوط الإجتماعية. & 10 \\
\hline$* * 0.675$ & 1 القدرة على إيجاد حلول جدية للمشكلات. & 11 \\
\hline
\end{tabular}

ج- التعرف على العوامل ذات القدرة على تفسير التغيرات في درجة التوني

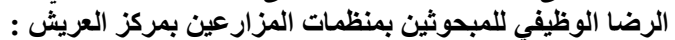

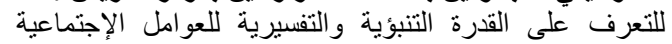

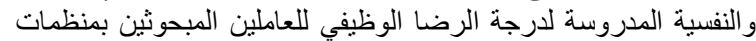

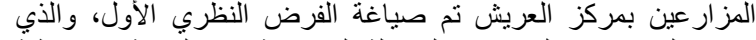
ينص على " تسهم المتغيرات المستقلة المدروسة ذاتئة ذات العلاقة الإرتباطية

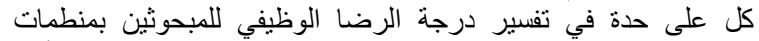

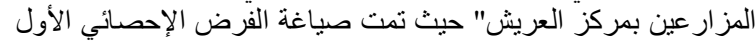

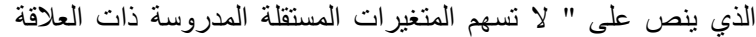

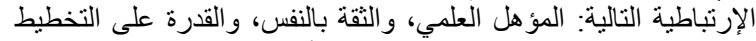

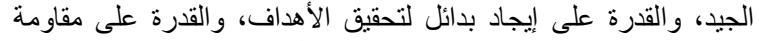

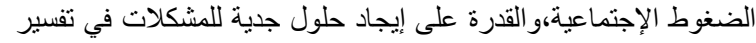

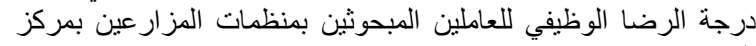

وقد تم استخدام أسلوب تحليل الإنحدار المرحلى ( Step -Wise ( regression analysis

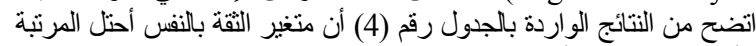

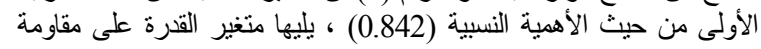

ثاتيا : التعرف على درجة الرضا الوظيفى للعاملين بالمنظمات

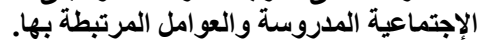

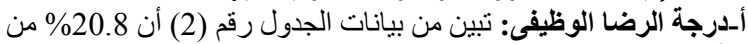

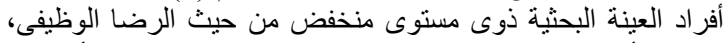

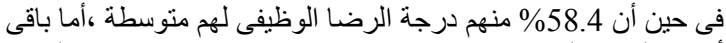

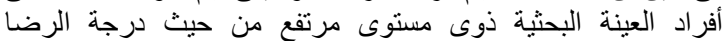

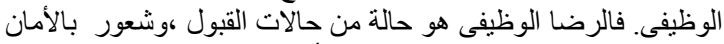

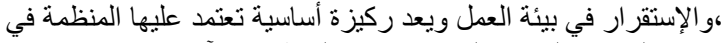

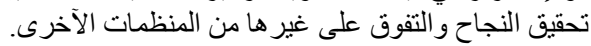

\begin{tabular}{|c|c|c|}
\hline$\%$ & العدد & الرضا الوظيفي \\
\hline 20.8 & 25 & منخفض(19-44) \\
\hline 58.4 & 70 & متوسط(45-50) \\
\hline 20.8 & 25 & مرتفع(51-95) \\
\hline 100 & 120 & الإجمالى \\
\hline
\end{tabular}

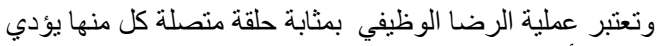

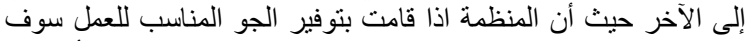

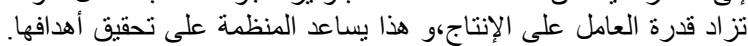

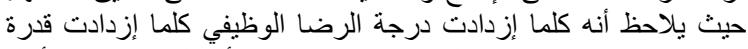

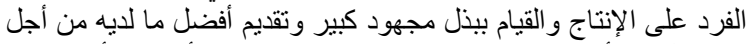

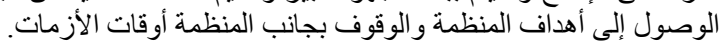

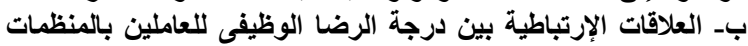

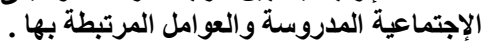

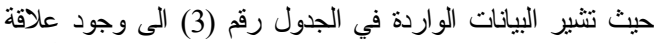

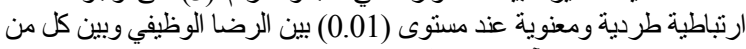

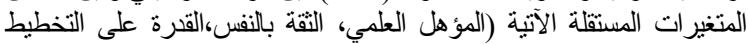

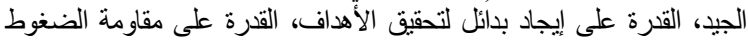

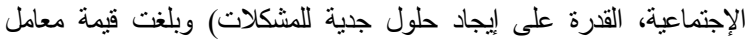

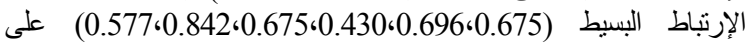

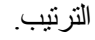


المرروسة ذات العلاقة الإرنباطية التالية: المؤهل العلمي، والمستوى الوظيفي، ولئي

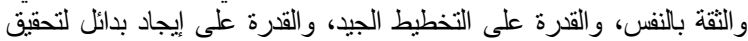

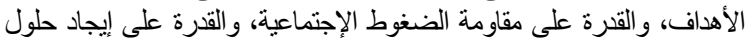

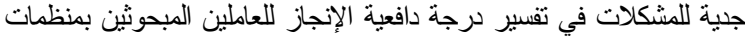

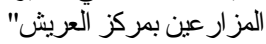

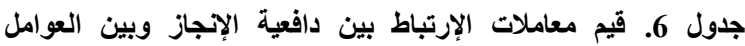

\begin{tabular}{|c|c|}
\hline قَيم معاملة الإنجاز & العوامل الإجتماعية والنفسية \\
\hline $\begin{array}{c}0.050- \\
* * 0.576\end{array}$ & \\
\hline *0.189- & المص \\
\hline 0.059 & عدد سنو \\
\hline 0.061 & 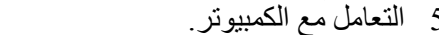 \\
\hline 0.099 & درجة \\
\hline$* * 0.801$ & الثقة بال \\
\hline$* * 0.706$ & القدرة على التخط \\
\hline$* * 0.433$ & بدائل لتحقيق الاهداف. \\
\hline$* * 0.668$ & ضنغوط الإجتماعية. \\
\hline$* * 0.706$ & إيجاد حلول جدية للمشكلات. \\
\hline
\end{tabular}

وقد نم استخدام أسلوب تحليل الإنحدار المرحلى ( Step -Wise

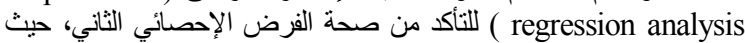

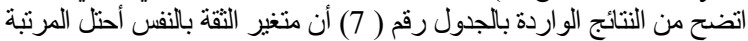

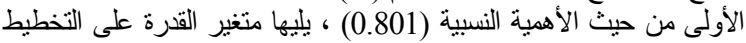

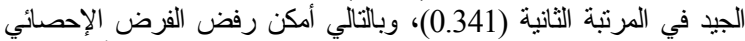

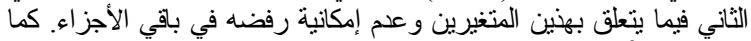

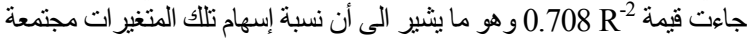

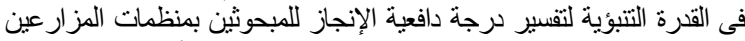

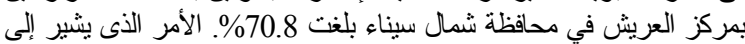

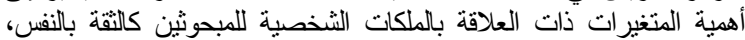
والقدرة على التخطيط في التأثير على درجة دات دافعية الإنجاز اللعاملين بمنظمات المزارعين المبحوثين في مركز العريش.

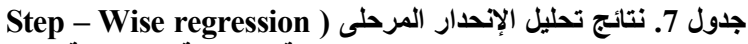
(analysis دافة دافعية الإنجاز

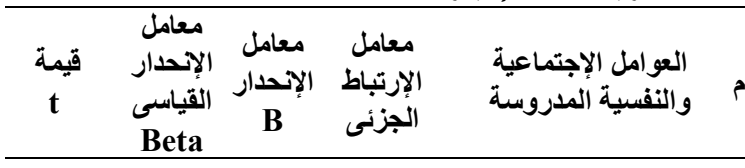

\begin{tabular}{llllll}
\hline$* * 14.52$ & 0.801 & 1.603 & $* 0.516$ & 1
\end{tabular}

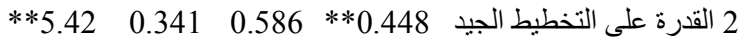

\begin{tabular}{|c|c|}
\hline $\bar{F}=145.404 * *$ & $R^{-2}=0.708$ \\
\hline
\end{tabular}

رابعا : التعرف على المجالات التريبية لرفع قرات الترات العاملين في منظمات

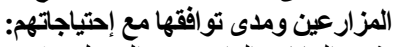

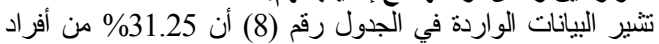

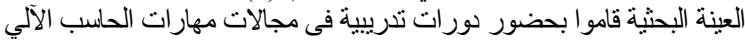

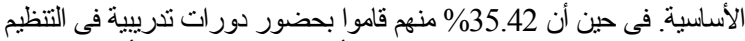

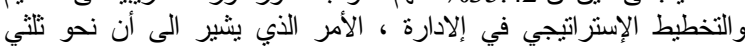

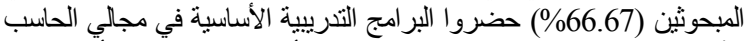

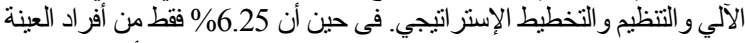

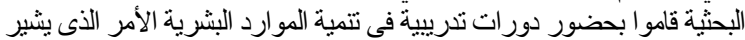

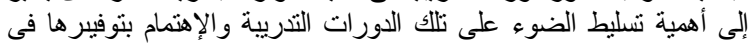

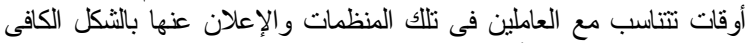

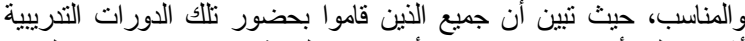

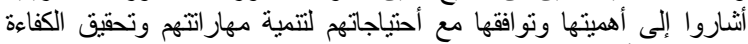

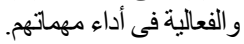

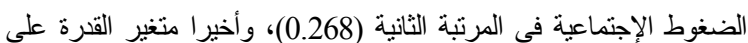

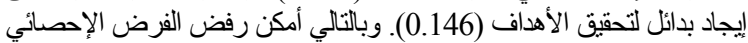

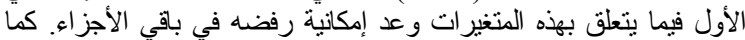

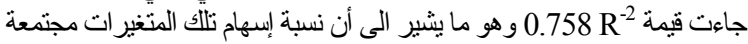

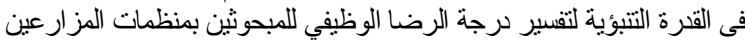

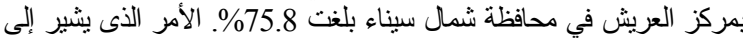

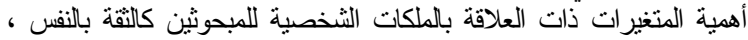

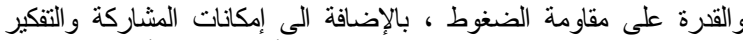

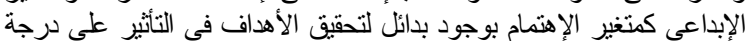
الرضا الوظيفي للعاملين بمنظمات المزار بونين في مركز العريش.

جدول 4. نتائج تحليل الإنحار المرحلى ( Step - Wise regression (analysis درجة الرضا الوظيفي لين العوالي

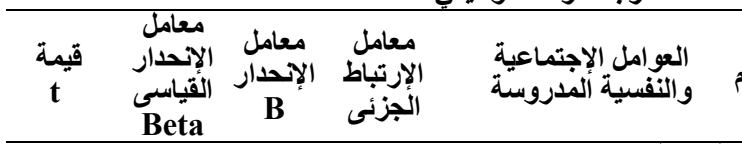

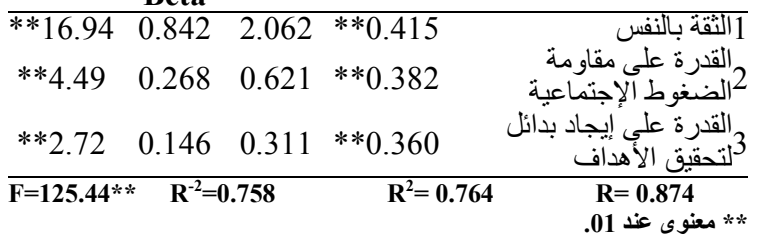

ثالثا : التعرف على درجة دافعية الإجاز للعاملين بالمنظمات الإجتماعية

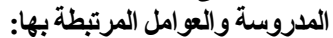

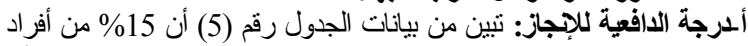

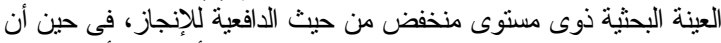

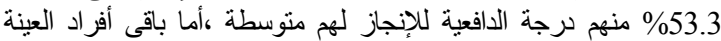

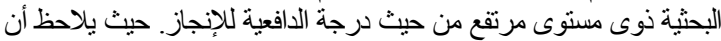

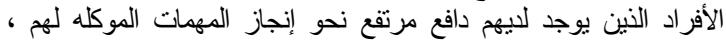

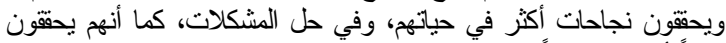
تقدماً أكثر وضوحاً في المجتمع. والمرتفعون في دافع الإنجاز واقعيون في التهات استغلال الفرص وضتحقيق الأهداف.

جدول 5. التوزيع العددى والنسبي للمبحوثين وفقاً للافوفية للإنجاز

\begin{tabular}{|c|c|c|}
\hline$\%$ & العدد & الآلفعية للإنجاز \\
\hline 15 & 18 & منخفض(13-30) \\
\hline 53.3 & 64 & متوسط(48-31) \\
\hline 31.7 & 38 & مرتفع(49-65) \\
\hline 100 & 120 & الإجمالى \\
\hline
\end{tabular}

ب-العلاقات الإرتباطية بين درجة دافعية الإنجاز للعاملين بالمنظمات

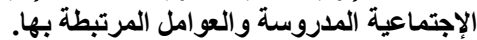

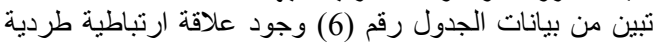

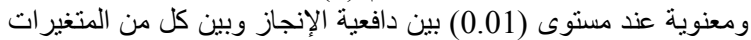

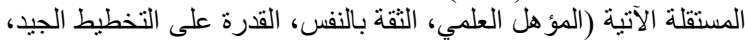

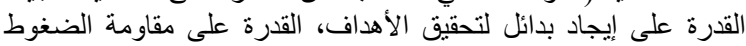
الإجتماعية، القدرة على إيجاد حلول جدية للمشكلات) وبلغت الإن قيمة معامل

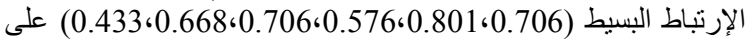

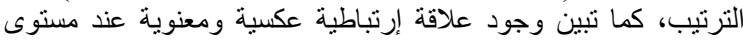

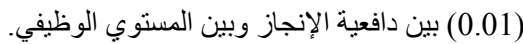

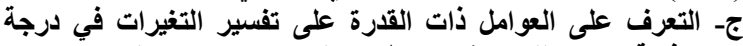

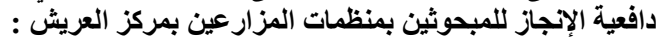

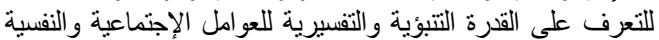

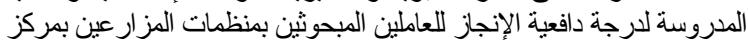

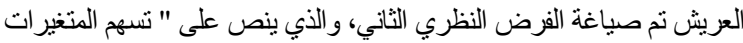

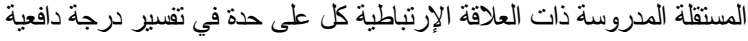
الإنجاز اللمبحوثين بمنطمات المزارين الإرين بمركز العريش" حيث حيث تمت صياغة

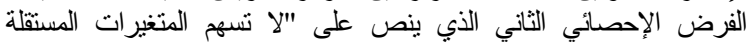


Hassan, M. M. and A. E. A. Betah

جدول 8. يوضح مجالات الدورات التدريبية ومدى توافقها مع الإحتياجات

\begin{tabular}{|c|c|c|c|c|c|c|}
\hline \multicolumn{4}{|c|}{ مدى توافق الاورات التّريبية مع الإحتياجات } & \multirow{3}{*}{$\%$} & \multirow{3}{*}{ 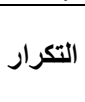 } & \multirow{3}{*}{ مجالات الدورات التدريبية } \\
\hline \multicolumn{2}{|c|}{ غير متوافق } & \multicolumn{2}{|c|}{ متوافق } & & & \\
\hline$\%$ & عدد & $\%$ & عدد & & & \\
\hline 6.67 & 1 & 93.33 & 14 & 31.25 & 15 & 1-مهارات الحاسب الاللي الأساسية. \\
\hline 0.00 & 0 & 100.00 & 3 & 6.25 & 3 & 2-تنمياً \\
\hline 41.18 & 7 & 58.82 & 10 & 35.42 & 17 & 3-التتظيم والتخطبط الاستر اتيجي في إلادارة. \\
\hline 50.00 & 3 & 50.00 & 3 & 12.50 & 6 & 4-التسويق الإكتروني وتنمية الموّاردّ. \\
\hline 20.00 & 1 & 80.00 & 4 & 10.42 & 5 & 5-شُئون عاملين. \\
\hline 0.00 & 0 & 100.00 & 3 & 6.25 & 3 & 6-كيفية التعامل مع إدارة الازمات. \\
\hline 14.29 & 1 & 85.71 & 6 & 14.58 & 7 & 7ـالمحتاسبة و الإدارةة المالية. \\
\hline
\end{tabular}

النسبية لمقترحات المبحوثين لتحسين حالة الرضا الوظيفي وتعظيم دافعية الإنجاز

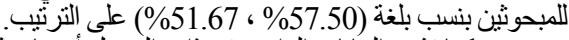

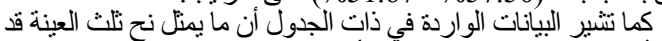

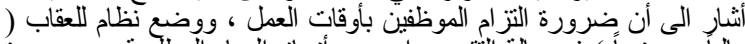

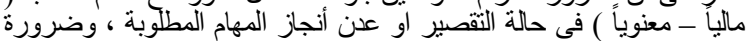

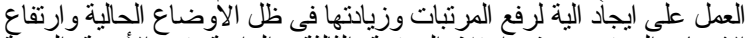

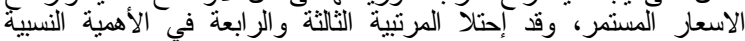

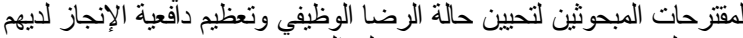
بنسب بلغت (35.00\% ، 33.33\%) على الترتيب.

خامسا : مقترحات المبحوثين لتحسين حالة الرضا الوظيفي وتعظيم دافعية

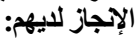

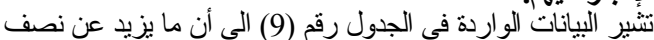

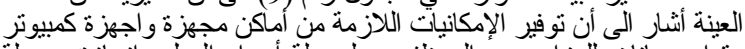

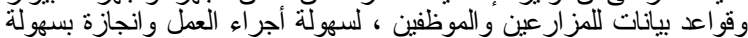

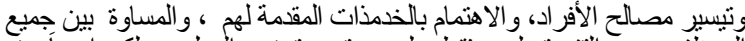

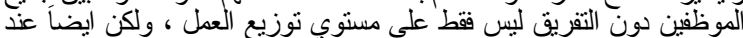

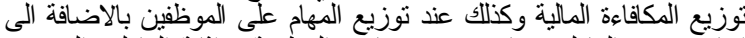

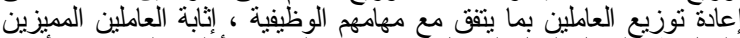
بالعمل طبقا لمعدل العمل المبذول ، وقد إحتلا المرتبة الأولى والثانية في الأهمية

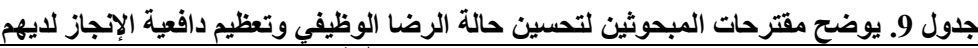

\begin{tabular}{|c|c|c|}
\hline$\%$ & 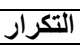 & المقترح \\
\hline 57.50 & 69 & 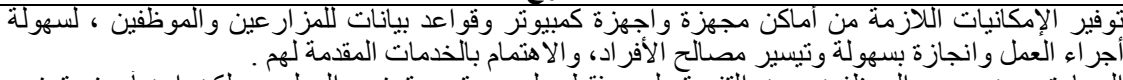 \\
\hline 51.67 & 62 & 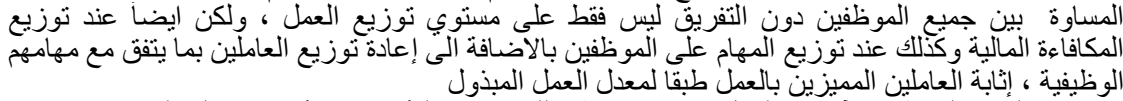 \\
\hline 35.00 & 42 & ـوضع نظام للعقاب ( ماليا - معنويا ) فى حالة التقصبر او عدن \\
\hline 33.33 & 40 & هاد الية لرفع المرتبات وزيادتها فى ظل الاوضاع الحالية وارتفاع الاسعار المستمر . . \\
\hline 20.83 & 25 & 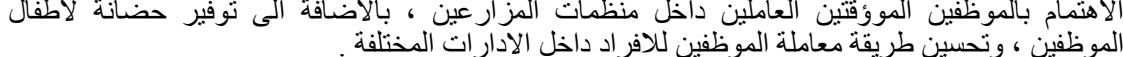 \\
\hline 16.67 & 20 & النظر في تخطيط المدينة من ناحية تعديل طريق الخدمة الساحلي و الاهتمام بنظافة الثو ارع . \\
\hline 13.33 & 16 & توفير فرص عمل للشباب و الا هتمام بمقترحات الثباب \\
\hline 5.00 & 6 & 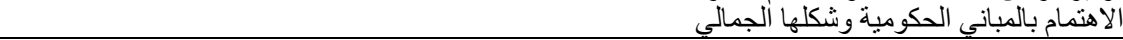 \\
\hline
\end{tabular}

الأداء، و توفير جو من المساواة في التعامل مع العاملين في جميع مجالات التاتئ

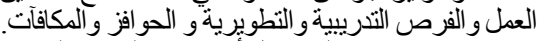
7- إجر اء در اسات مستقبلية تشمل أخرى يتتاولها هذا البحث. المراجع

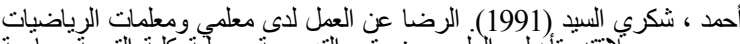

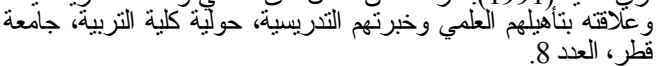

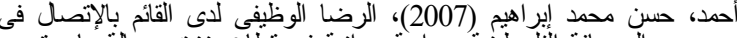

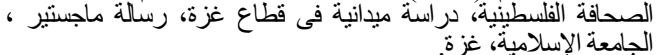

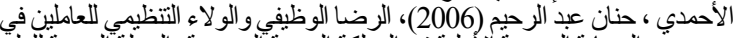

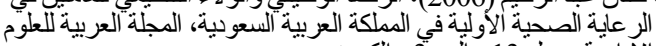

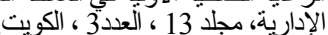

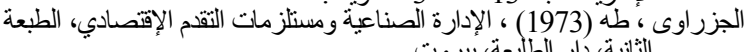

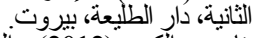

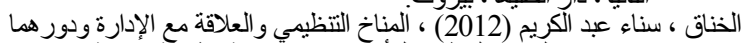

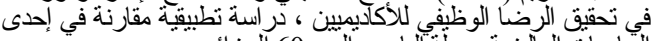

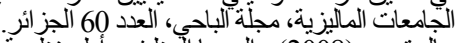

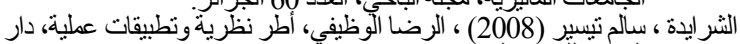

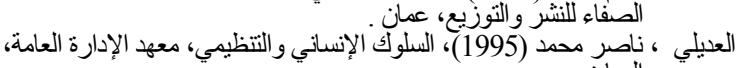

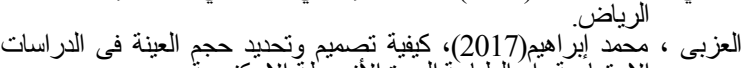

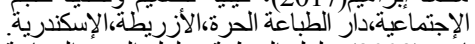

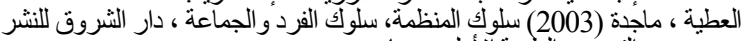

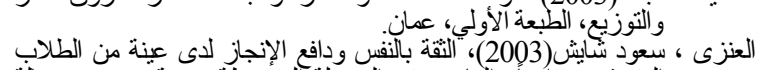

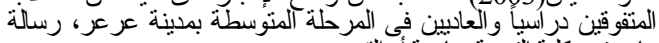

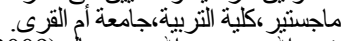

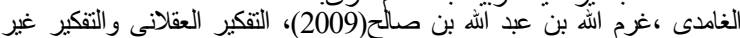

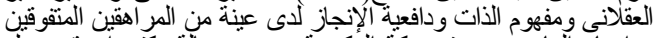

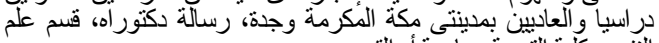

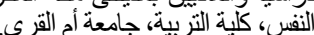

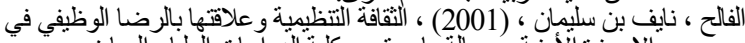
الاجززة الأمنية ، رسالة ماجستير ، كلية الكر استات العليا ، الرياض.

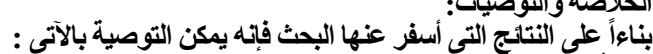

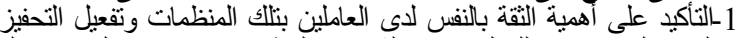

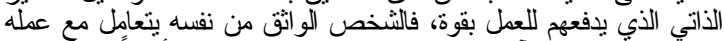

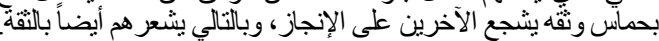

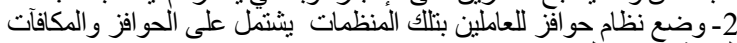

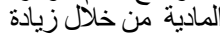

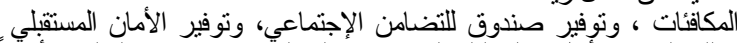

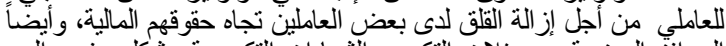

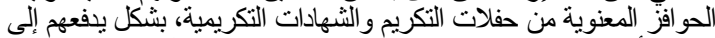

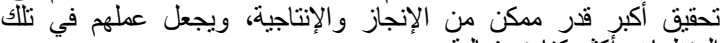
المنظمات أكثر كفاءة وفعالية.

3- توفير فرص النمو المهني لجميع العاملين بتلك المنظمية المنات من خلال دعم

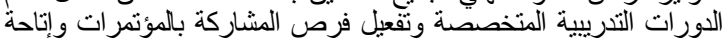

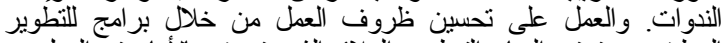

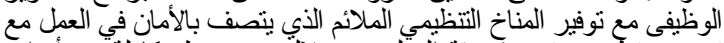

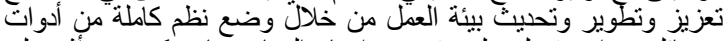

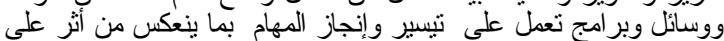
الرضا الوظيفي للعاملين.

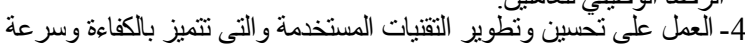

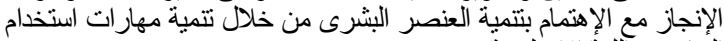
الحاسب وآللغة الإنجليزية.

5- تعزيز وتوطيد العلاقة بين الإدارة وبين جميع العاملين داخل المنظمة من أجل الإلئ

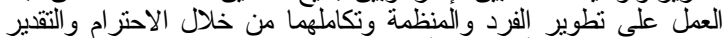

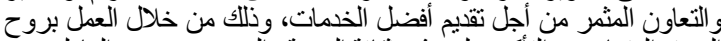

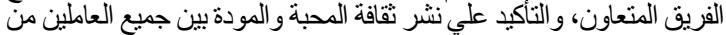

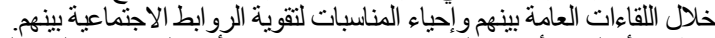

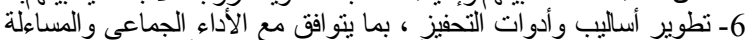

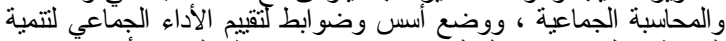

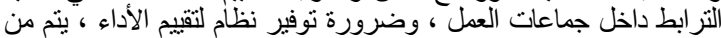

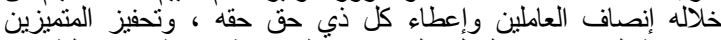
ومحاسبة المقصرين، والعمل علي توفير نظّام تغذية راجعة تتبع عملية تقييم 
عباس ، سعيلة محمد(2006) ، إدارة الموارد البشرية مدخل إستراتيجي، الطبعة

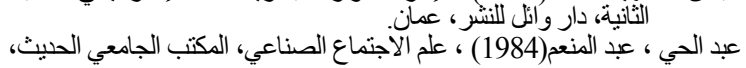

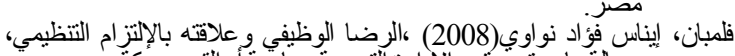

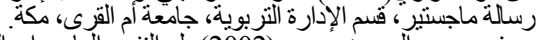

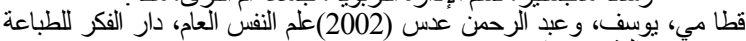

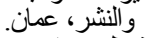

محافظة شمال سيناء، مركز النس المعلومات ودعم اتخاذ القرار ،تاريخ البيان: 2012 / 2013

Eisenberger.(1997). Perceived organizational support and discretionary treatment, and job satisfaction. Journal of Applied Psychology, 82, 812-820. http://dx.doi.org/10.1037/0021-9010.82.5.812

Joseph, Manceil Anqus, , (1993). "Principal Instructional Management and its Relation to Teacher job Salifaction", DAI. A 53/11, P, 3758.

Judge, T. A., Thoresen, C. J., Bono, J. E., \& Patton, G. K. (2001). The job satisfaction-job performance relationship. Psychological Bulletin, 127(3), 376-407. http://dx.doi.org/10.1037/0033-2909. 127. 3. 376

ME, Sermpene, Job Satisfaction in Relation to Organizational Culture, Journal of Industrial psychology, 28(2), 2002, p23.

Saari and T. A. Judge, "Employee Attitudes and Job Satisfaction," Human Resource Management 43, no. 4 (2004).

Seashore, S. E., \& Tobor, T. D. (1975). Job satisfaction and their correlation. American Behavioural Scientist, 18, 333-368. http://dx. doi.org/10. 1177/ 0002764 27501800303

Song, L. J., Tsui, A. S., \& Law, K. S. (2009). Unpacking employee responses to organizational exchange mechanisms: the role of social and economic exchange perception? Journal of Management, 35, 56-93. http://dx. doi.org/10. 177/ 0149206308321544

Tharrington, Donnie Everetle, 1993- perceived principal leaderships Behaviour and Reported Teacher Job Satisfaction. (leadership behaviour) DATA, 53 / 07. P. 2198.

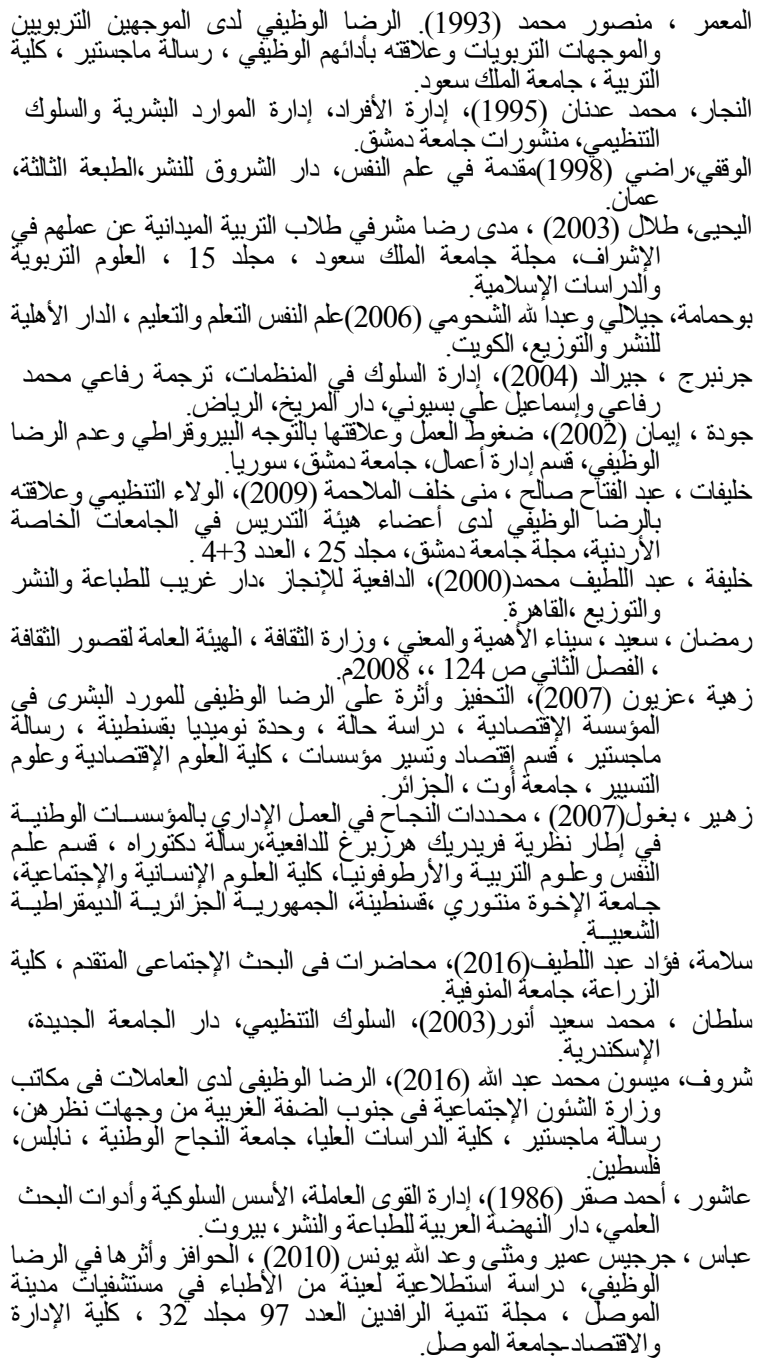

\section{Some Factors Determining the Degree of Job Satisfaction and Achievement Motivation of some Farmers' Organizations Employees in El-Arish District in North Sinai Governorate Hassan, M. M. and A. E. A. Betah \\ ${ }^{1}$ Rural Sociology Fac.Of Environmental Agricultural Sciences El-Arish University \\ ${ }^{2}$ Rural Sociology College of Agriculture, Saba Basha Alexandria University}

\section{ABSTRACT}

The research was conducted to identify some factors determining the degree of job satisfaction and achievement motivation of some farmers' organizations employees in El-Arish district in North Sinai Governorate, as well as identifying the training domains to raise their compatibility. As well as identify their ideas to improve the job satisfaction and achievement.The research data was collected from respondents, through face-to-face questionnaire after conducting pre-test study. The sample size was 120 respondents. Some statistical methods were used to describe and analyse data as percentages, measures of central tendency, and measures of dispersion, Alpha-Cronbach, Pearson simple correlation coefficient, and Step -Wise regression analysis, through using of Statistical Package for the Social Sciences (SPSS).The research results revealed a significant relationship at (0.01) level between each of job satisfaction and achievement motivation of some farmers' organizations employees and between each of(educational qualifications, self-confidence, alternatives for target achievement , good planning, resist social pressures, problem solving).Step - Wise regression analysis has shown that self-confidence was ranked first, resistance to social pressures was ranked second and finally the variable of alternatives for target achievement in terms of the relative importance in influencing of job satisfaction, farther more Step - Wise regression analysis has shown that self-confidence was ranked first and finally the variable of good planning in terms of the relative importance in influencing of achievement motivation. The research was concluded with some recommendations. The most important of which is establishment a system of incentives for the employees. Moreover, providing professional growth opportunities for all employees through supporting specialized training courses and encourage participation in conferences.

Keywords: Farmers' organizations, job satisfaction, achievement motivation. 